\title{
Turbulence Asymmetries in Bottom Boundary Layer Velocity Pulses Associated with Onshore-Propagating Nonlinear Internal Waves
}

\author{
JOHANNES BECHERER \\ College of Earth, Ocean, and Atmospheric Sciences, Oregon State University, Corvallis, Oregon, and \\ Helmholtz-Zentrum Geesthacht, Institute of Coastal Research, Geesthacht, Germany \\ JAMES N. MOUM \\ College of Earth, Ocean, and Atmospheric Sciences, Oregon State University, Corvallis, Oregon \\ JOHN A. COLOSI \\ Department of Oceanography, Naval Postgraduate School, Monterey Bay, California \\ JAMES A. LERCZAK AND JACQUELINE M. MCSWEENEY \\ College of Earth, Ocean, and Atmospheric Sciences, Oregon State University, Corvallis, Oregon
}

(Manuscript received 1 August 2019, in final form 19 June 2020)

\begin{abstract}
The inner shelf is a region inshore of that part of the shelf that roughly obeys Ekman dynamics and offshore of the surf zone. Importantly, this is where surface and bottom boundary layers are in close proximity, overlap, and interact. The internal tide carries a substantial amount of energy into the inner shelf region were it eventually dissipates and contributes to mixing. A part of this energy transformation is due to a complex interaction with the bottom, where distinctions between nonlinear internal waves of depression and elevation are blurred, indeed, where polarity reversals of incoming waves take place. From an intensive set of measurements over the inner shelf off central California, we identify salient differences between onshore pulses from waves with properties of elevation waves and offshore pulses from shallowing depression waves. While the velocity structures and amplitudes of on/offshore pulses $1 \mathrm{~m}$ above the seafloor are not detectably different, onshore pulses are both more energetically turbulent and carry more sediments than offshore pulses. Their turbulence is also oppositely skewed: onshore pulses slightly to the leading edges, offshore pulses to the trailing edges of the pulses. We consider in turn three independent mechanisms that may contribute to the observed asymmetry: propagation in adverse pressure gradients and the resultant inflection point instability, residence time of a fluid parcel in the pulse, and turbulence suppression by stratification. The first mechanism may largely explain higher turbulence in the trailing edge of offshore pulses. The extended residence time may be responsible for the high and more uniform turbulence distribution across onshore compared to offshore pulses. Stratification does not play a leading role in turbulence modification inside of the pulses $1 \mathrm{~m}$ above the bed.
\end{abstract}

\section{Introduction}

Large-amplitude nonlinear internal waves (NLIWs) are a commonly observed feature of the coastal ocean (Apel 2003). They are suspected to play a crucial role in the transport of energy, mass, nutrients, and sediment

\footnotetext{
Corresponding author: Johannes Becherer, johannes.becherer@ hzg.de
}

(Sandstrom and Elliott 1984; Shroyer et al. 2010; Pomar et al. 2012).

NLIWs are believed to be generated primarily by tidal currents interacting with the continental shelf break, sills, seamounts, or other bathymetrical features (Apel 2003). Under certain circumstances they can be released by sharp decelerating density fronts, as found in river plumes (Nash and Moum 2005).

Most commonly high-frequency NLIWs are observed in association with the internal tide. The internal tide 
often appears in form of so-called solibores ${ }^{1}$ (Henyey and Hoering 1997), where an initial train of high-frequency solitonlike NLIWs is followed by a low-frequency depression of the pycnocline, which slowly relaxes back to the initial state within a couple of hours (Apel 2003). As such, high-frequency NLIWs act as an intermediate step in the ocean's energy cascade from low-frequency phenomena like internal tides to small-scale turbulence, resulting in dissipation of kinetic energy and mixing. High-frequency NLIWs can carry a substantial fraction of the total baroclinic tidal energy (Sandstrom and Elliott 1984; Colosi et al. 2018). Understanding the link between NLIWs and turbulence is crucial to study where and how the internal tidal energy is eventually dissipated.

Despite the key role of NLIWs in the oceans' energy budget, we still understand surprisingly little about their actual dynamics. Due to their high-frequency nonlinear nature and rapid evolution, they are challenging to observe in the ocean or to simulate with numerical models.

Especially interesting and complicated are the shoaling dynamics of NLIWs. When they propagate into shallow waters and interact with the bottom, they can change polarity from waves of depression to waves of elevation once the pycnocline becomes closer to the bottom than the surface (Helfrich et al. 1984; Shroyer et al. 2009). How exactly this transformation takes place is not entirely clear.

There are multiple ways in which NLIWs can lose their energy to turbulence (Lamb 2014), the most dramatic being breaking at steep slopes (Klymak et al. 2011; Arthur and Fringer 2014) or where the waveguide intersects the bottom (Vlasenko and Hutter 2002; Aghsaee et al. 2010; Lamb 2014). During breaking the internal tide can also form near-bottom boluses that transport water farther up the continental slope (Venayagamoorthy and Fringer 2007; Bourgault et al. 2008; Walter et al. 2012, 2014)

Besides sudden breaking, NLIWs also gradually lose energy during their propagation over the shelf. The gradual loss of energy can be due to interfacial shear instabilities on the waveguide (Bogucki and Garrett 1993; Sandstrom and Oakey 1995; Moum et al. 2003; Barad and Fringer 2010; Lamb and Farmer 2011) or due to bottom friction, in a potentially complicated interaction with the bottom boundary layer (BBL). To estimate the latter it is common to assume that bottom friction of NLIWs can be modeled with the help of a quadratic drag law, where the square of the wave-induced near-bottom velocity is multiplied by a drag coefficient $C_{d}$ to estimate bottom stress (Sandstrom and Elliott 1984; Moum et al. 2007). In

\footnotetext{
${ }^{1}$ Solibores can also be referred to as undular bores. In this manuscript, we use the terms interchangeably.
}

this paper we show examples where this approach is over simplistic and does not account for the complicated interaction of NLIWs with the BBL.

One of the goals of this study is to provide reliable turbulence measurements to investigate the mechanisms at play in the complex interaction between BBL and NLIWs in a real ocean setting. To this end, we present data from a newly developed turbulence measurement device [see section 2(b)1], detecting more than 80 strong bottom pulses associated to NLIWs (detection algorithm is described in section 4c). Besides the detailed investigation of individual events, this dataset allows us to make statistical claims about the different behavior of on- and offshore pulses associated to different phases of NLIWs. We find a significant asymmetry between these two groups of pulses in terms of BBL turbulence and sediment suspension (section 5). We discuss this in terms of the seafloor pressure gradient across the pulses, the residence time of fluid parcels within the pulses and the suppression of turbulence by stratification in the pulses (section 6). Conclusions follow in section 7.

\section{Experiment}

\section{a. Field campaign}

The Inner Shelf Dynamics Experiment took place from September to November 2017 off Point Sal, central California coast (Fig. 1). A large number of moorings $(>150)$ were deployed on the shelf from 150-m water depth to the surf zone. Many of these moorings were arranged in pairs, where a $\mathrm{T}$ chain, measuring density throughout the entire water column, was collocated with a bottom lander with acoustic Doppler current profiler (ADCP) to measure velocity profiles through the water column.

The data presented in this manuscript originate from one of these lander-T chain combinations (OC50; see Fig. 1) at 50-m water depth, part of the northernmost mooring array of the experiment. A more detailed overview of the entire experiment can be found in Lerczak et al. (2019) and McSweeney et al. (2020).

OC50 was chosen for the analysis here for the following reasons:

- the record of BBL turbulence measurements at this location is the most complete and least contaminated of all the records in the experiment;

- farther inshore, in shallower waters, NLIW energy was smaller and at the same time the influence of the surface gravity waves larger, leading to stronger contamination of the measurements; and

- farther offshore (at MS100, for example) the NLIW waveguide is nearer the surface, and NLIWs interact less strongly with the bottom. 


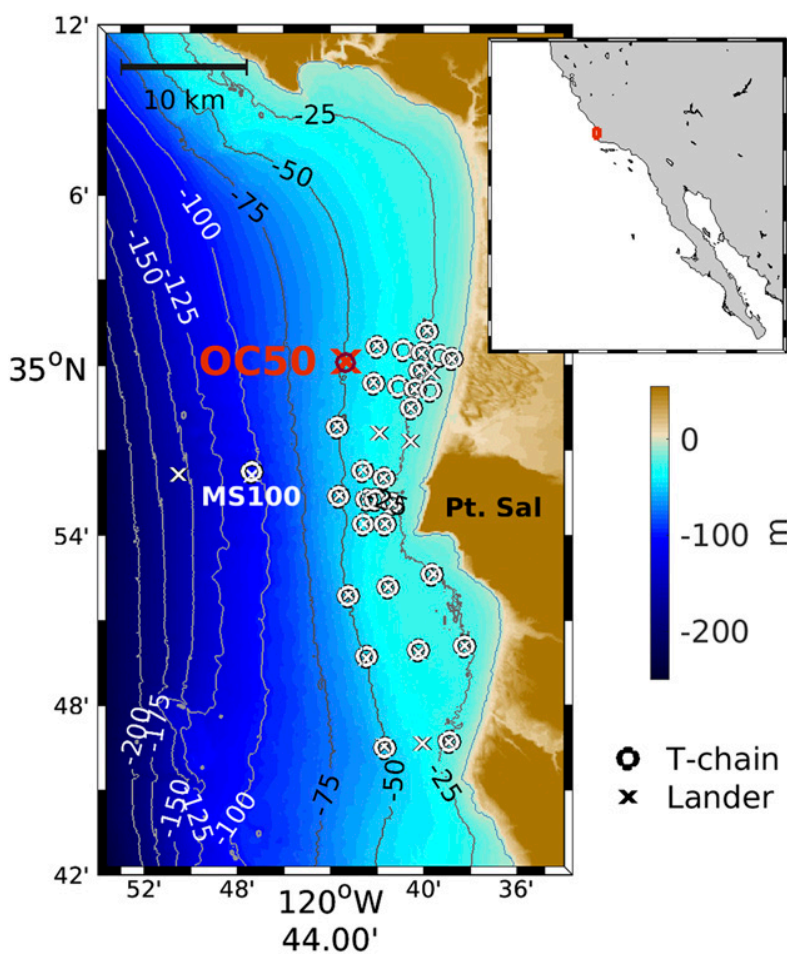

FIG. 1. Map of the study site. The position of all moorings deeper than $20 \mathrm{~m}$ are marked on the map, where circles denote $\mathrm{T}$ chains, and crosses denote landers. Mooring OC50 is highlighted with a red cross.

A more complete analysis of the time-dependent crossshelf structure of the NLIW field and turbulence appears in J. Becherer et al. (2020, unpublished manuscript). Our purpose here is to reconcile the structure of bottom boundary layer turbulence at a location where it is particularly well measured. The 19 days discussed herein, correspond to the full near-bottom turbulence record at OC50.

\section{b. Instrumentation}

\section{1) GusT}

GusT (pronounced "gusty") was developed specifically for the InnerShelf experiment, motivated by the objective of distributing multiple, identical, and inexpensive elements of a turbulence-measuring system throughout the experimental domain on all practical stationary or mobile vehicles (e.g., on the seafloor lander shown in Fig. 2). GusT is small $(57 \mathrm{~cm}$ long including sensors and tail plug, 6.4-cm diameter) and lightweight $(2.3 \mathrm{~kg}$ in air, $0.8 \mathrm{~kg}$ in water). Sensors include pitch, roll, and compass (4-Hz sample rate); 3-axis linear accelerometers; pressure sensor; a fast response temperature sensor (FP07, Thermometrics); and a pitot-static tube (Moum 2015). The latter group of sensors are sampled at $100 \mathrm{~Hz}$. With two Li D-cell batteries and $32 \mathrm{~GB}$ compact flash storage device, the deployment limit is 45 days.

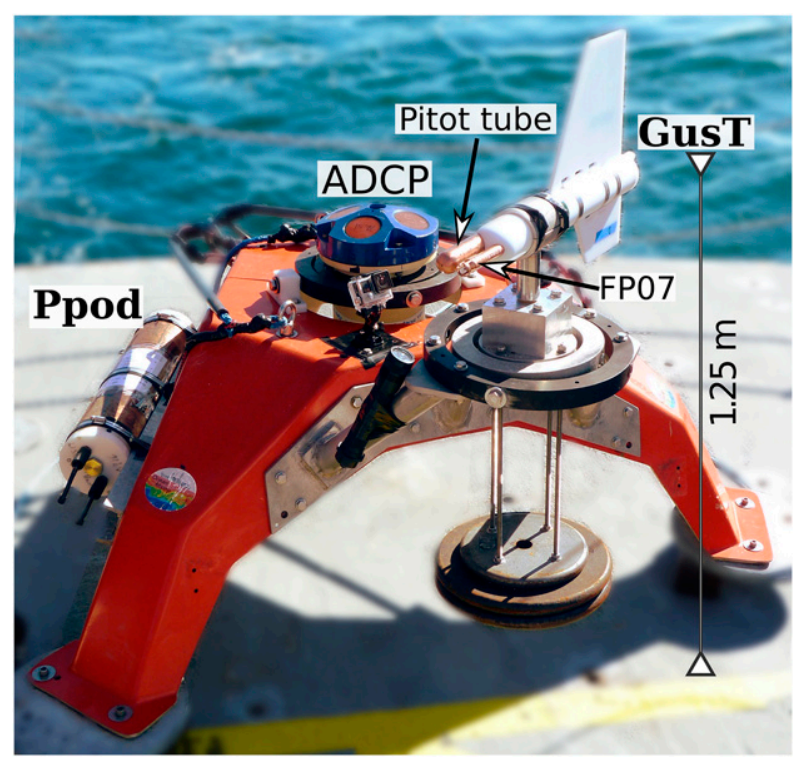

FIG. 2. Instrument configuration of the seafloor lander at OC50 (sea spider). The transducer head of the ADCP is mounted at $1 \mathrm{~m}$, the sensors of the GusT probe (pitot tube and fast thermistor, FP07) at $1.25 \mathrm{~m}$, and the Ppod at $0.3 \mathrm{~m}$ above the bed. Note that the ADCP on this photo is different from the one used on OC50. The rest of the lander configuration is, however, identical.

For the InnerShelf experiment, 80 GusTs were constructed and 75 were deployed at various times and in many different configurations, ranging from vessel-towed platforms to moored $\mathrm{T}$ chains and seafloor landers such as shown in Fig. 2, the focus of the discussion in this paper.

The pitot-static tube on GusT provides a point measurement of speed in the sensor direction (Moum 2015). Comparisons of pitot-static speed measurements on moored sensors in 65- and 100-m water depths off Kayak Island, Alaska, and $2000 \mathrm{~m}$ in Luzon Strait (Moum 2015) and at $30 \mathrm{~m}$ in the equatorial Atlantic cold tongue (Becherer and Moum 2017) with local speed measurements from adjacent ADCPs give confidence in the measurement technique. Comparisons of speed from the pitot-static tube and ADCP measurements discussed here show good agreement with considerable point-topoint scatter (Fig. 3). The scatter is to be expected when comparing a true local and point measurement with a considerably less well-sampled ADCP measurement that is only roughly collocated vertically and laterally.

GusT is intended to be steered into the flow. The velocity components $u_{p}$ (onshore) and $v_{p}$ (alongshore) are derived from the speed $s_{p}=\sqrt{u_{p}^{2}+v_{p}^{2}}$ by utilizing the internal compass of GusT. On the seafloor lander in Fig. 2, GusT was gimbaled to maintain its vertical orientation and vaned into the flow on a low-friction bearing. In moored applications, GusT was clamped to the mooring cable and vaned into the flow by opposing 


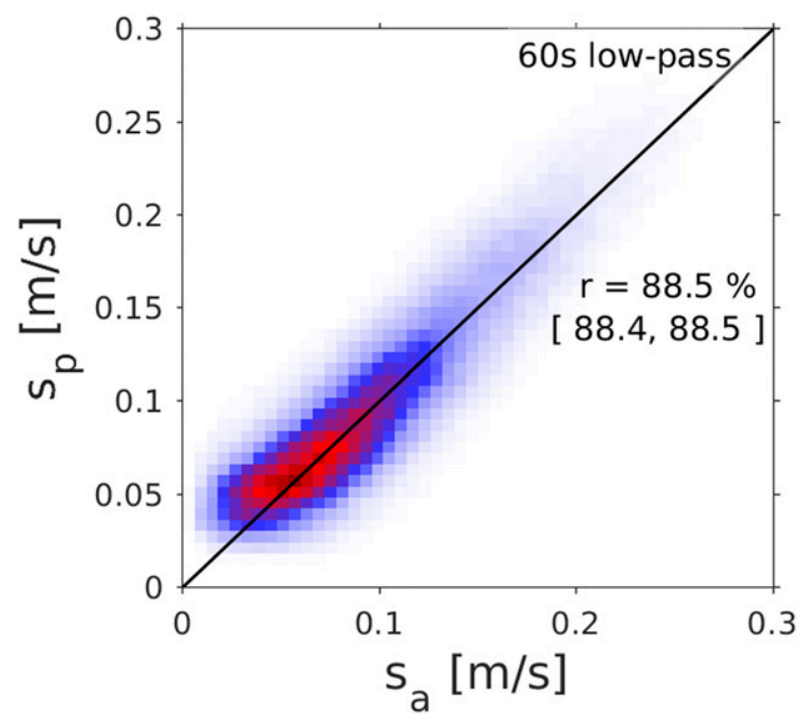

FIG. 3. Mean speed $s_{p}$ (60-s low-pass filter), measured by the GusT's pitot tube ( $1.25 \mathrm{~m}$ above the bed) compared to the comparable estimate $s_{a}$ from the lowest bin of the ADCP $1.5 \mathrm{~m}$ above the bed.

the relatively weak torsional rigidity of the cable, as we have successfully done with moored $\chi$ pods (Moum and Nash 2009).

In addition, GusT yields two independent measurements of the turbulence. From scaling of gradient spectra derived from thermistor measurements, we estimate the dissipation of temperature gradient variance, $\chi$ following the methods described by Moum and Nash (2009), Zhang and Moum (2010), and Becherer and Moum (2017). From this is further derived the turbulence diffusivity $K_{T}$ and the viscous dissipation rate of turbulent kinetic energy $\varepsilon_{\chi}$. Strong verification of these methods by comparison of moored $\chi$ pod estimates of $\varepsilon_{\chi}$ to more established profiler estimates of $\varepsilon$ using airfoil probes has been demonstrated by Perlin and Moum (2012) and Pujiana et al. (2018).

The second direct estimate of turbulence is derived by scaling of the velocity gradient spectrum (Fig. A1) measured by the pitot-static tube (Moum 2015). This yields a direct estimate of $\varepsilon$ and is the primary metric of the turbulence used in this paper. Details on the latter method, including necessary calculations, assumptions, and interdependencies, are included in the appendix.

To measure the natural turbulence, the turbulence measurements must avoid contamination by upstream objects and be steered into the instantaneous flow (within $\pm 45^{\circ}$ for the thermistor and $\pm 10^{\circ}$ for the pitotstatic tube, determined by its cosine response to speed). In shallow water with no mean flow, wave orbitals define the instantaneous flow, the vaning of GusT turns it so that it is out of phase with the instantaneous flow and the measurements are not properly steered into the flow. When the mean flow is sufficiently large compared to the wave orbitals the GusT slowly vanes into the instantaneous flow within our limits. In this paper, the data flagged from analysis are primarily due to low ratios of mean/orbital speeds. A detailed description of the flagging scheme can be found in the appendix.

\section{2) LANDER SETUP}

The configuration of the lander discussed in this manuscript is shown in Fig. 2. The instruments include a gimbaled ADCP in the middle, a high-resolution pressure sensor that we have configured and refer to as Ppod on one side brace, and the gimbaled and vaned GusT on an extended arm to the side and positioned $0.25 \mathrm{~m}$ above the ADCP head.

The ADCP in the center used on this lander was a Nortek Signature 500. This is a 5-beam ADCP with acoustic frequency of $500 \mathrm{kHz}$. The ADCP pinged at $2 \mathrm{~Hz}$ and averaged every $2 \mathrm{~s}$. The bin width was 0.5 with the bottommost bin at $1.5 \mathrm{~m}$ above the bed.

The Ppod is a device that measures high-resolution pressure fluctuations at a sampling frequency of $1 \mathrm{~Hz}$ (Moum and Nash 2008; Stöeber and Moum 2011; Warner et al. 2013).

\section{3) T CHAIN}

Attached to the T chain at OC50 were 23 fast-sampling thermistors (RBRSoloT, $1 \mathrm{~Hz}$ sampling frequency), a Sea-Bird MicroCAT37 CTD to measure conductivity and temperature at $16.5-\mathrm{m}$ depth, as well as five GusTs between 15- and 35-m depth. This resulted in an average vertical resolution for temperature of less than $2 \mathrm{~m}$, with the spacing in the anticipated thermocline region (middle of the water column) close to $1 \mathrm{~m}$. Note that the CTD data confirm that salinity stratification is negligible compared to temperature, which allows for direct estimation of density from the temperature measurements alone.

The lander was deployed $100 \mathrm{~m}$ northeast of the $\mathrm{T}$ chain. For wave phase speed of $0.2 \mathrm{~m} \mathrm{~s}^{-1}$, this results in a phase delay between lander and $\mathrm{T}$ chain of up to $500 \mathrm{~s}$, for the range of wave propagation directions found by triangulation (McSweeney et al. 2020). Both phase speed and direction of the high-frequency NLIWs changed in time. Since it was not possible to simply correct for the time delay between lander and $\mathrm{T}$ chain with a constant offset, we first cross correlated the time derivative of the isothermal displacement measured at the $\mathrm{T}$ chain with the vertical velocity measured with the 
$\mathrm{ADCP}$ at the lander to calculate a time-dependent phase delay. This time-dependent phase delay was then used to adjust the timing for the T-chain data such that they are synchronized with the lander data. A problem with this approach is that it cannot account for the evolution of the wave field between the two measurement points.

\section{The nature of near-bottom velocity pulses}

The source of near-bottom velocity pulses is the incoming internal bore and accompanying large-amplitude high-frequency internal waves that appeared roughly twice per $\mathrm{M}_{2}$ tidal cycle over the shelf within the experimental domain (McSweeney et al. 2020). The bores were clearly identified at the 100-m isobath (MS100; see Fig. 1) and evolved considerably as they propagated through shallowing waters. Taken together we refer to bores and high-frequency waves as nonlinear internal waves.

At the 50-m isobath (OC50), the pycnocline depth ahead of the bores was typically closer to the surface than to the bottom. If the pycnocline is sufficiently strong, its depth determines the sign of the nonlinear waves that propagate along it (Helfrich et al. 1984; Shroyer et al. 2009). When the pycnocline is nearer the surface, waves that depress the pycnocline are preferred; when the pycnocline is nearer the bottom, waves that elevate the pycnocline are preferred. In the representative examples shown in Fig. 4 the prebore pycnocline was about $10 \mathrm{~m}$ deep, or $20 \%$ of the water column.

The structure of the large-amplitude wave signal at the $50-\mathrm{m}$ isobath took many forms, representative examples of which are included in Fig. 4. They included what appear to be

- a single solitary wave (Fig. 4f);

- an undular bore or a solitary wave fissioning from the bore (Fig. 4a);

- a train of solitary-like waves of alternating polarity (depression/elevation; Fig. 4k); and

- a bore with trailing elevation waves (Fig. 4p).

Immediately above the seafloor, a solitary wave of depression propagating onshore appears as an offshore velocity pulse. In contrast, a solitary wave of elevation appears as an onshore velocity pulse.

For the remainder of this paper, we refer simply to onshore and offshore pulses, implying that these are pulses in velocity immediately above the seafloor, and leave the ambiguity of waveform aside. We identify these pulses directly from the sign and magnitude of near-bottom velocity. At the same time, we acknowledge that near-bottom offshore pulses are solely associated with isopycnal depressions and onshore pulses with isopycnal elevations.

\section{Analysis methods}

Here we describe the relevant wave properties and the detection algorithm used to find pulses but first briefly review the law of the wall as applied to turbulent boundary layers.

\section{a. Law of the wall}

Direct estimates of the rate of viscous dissipation of turbulent kinetic energy $\varepsilon_{p}$ through scaling of velocity spectra obtained from the GusT pitot-static tube (appendix) are compared to the prediction based on unstratified turbulent boundary layers, the law of the wall (Pope 2000)

$$
\varepsilon_{\mathrm{bbl}}=\frac{u_{*}^{3}}{\kappa z},
$$

where $\kappa=0.4$ is von Kármán's constant, and the friction velocity

$$
u_{*}^{2}=C_{d}(z) s(z)^{2}
$$

with $s(z)$ being the flow speed at a distance $z$ from the bed. The drag coefficient

$$
C_{d}(z)=\kappa^{2} \ln ^{-2}\left(\frac{z}{z_{0}}\right)
$$

depends on $z$ and the roughness parameter $z_{0}$. Here, we use $\varepsilon_{\mathrm{bbl}}$ as a metric for comparison to our estimate from the pitot-static tube $\varepsilon_{p}$ to indicate where they are in agreement and more importantly, when and where they differ.

\section{b. Wave properties}

From the ADCP measurements of vertical velocity $w_{a}$, we define the time-dependent depth-average isopycnal displacement $t^{2}$

$$
\eta(t)=\int_{0}^{t}\left[\frac{1}{H} \int_{0}^{H} w_{a}\left(t^{\prime}, z\right) d z\right]^{\mathrm{bp}} d t^{\prime}
$$

where $t^{\prime}$ is the integration variable, and $[\cdot]^{\text {bp }}$ a bandpass filter (30-1200s). The peak value of $\eta(t)$ during each bottom-pulse event is then used as a measure of the corresponding maximum isopycnal displacement $\eta_{0}$,

\footnotetext{
${ }^{2}$ Alternatively, it is possible to use the T-chain data to calculate isopycnal displacement directly. For most waves, these two methods agree well (see Fig. 4b). The key advantage of using ADCP over T-chain data is that the ADCP is mounted on the same lander as the GusT, whereas the T chain is $O(100) \mathrm{m}$ away. Even after time correction, this relatively short distance can lead to significant decorrelation between $T$ chain and lander for some of the highfrequency NLIWs.
} 

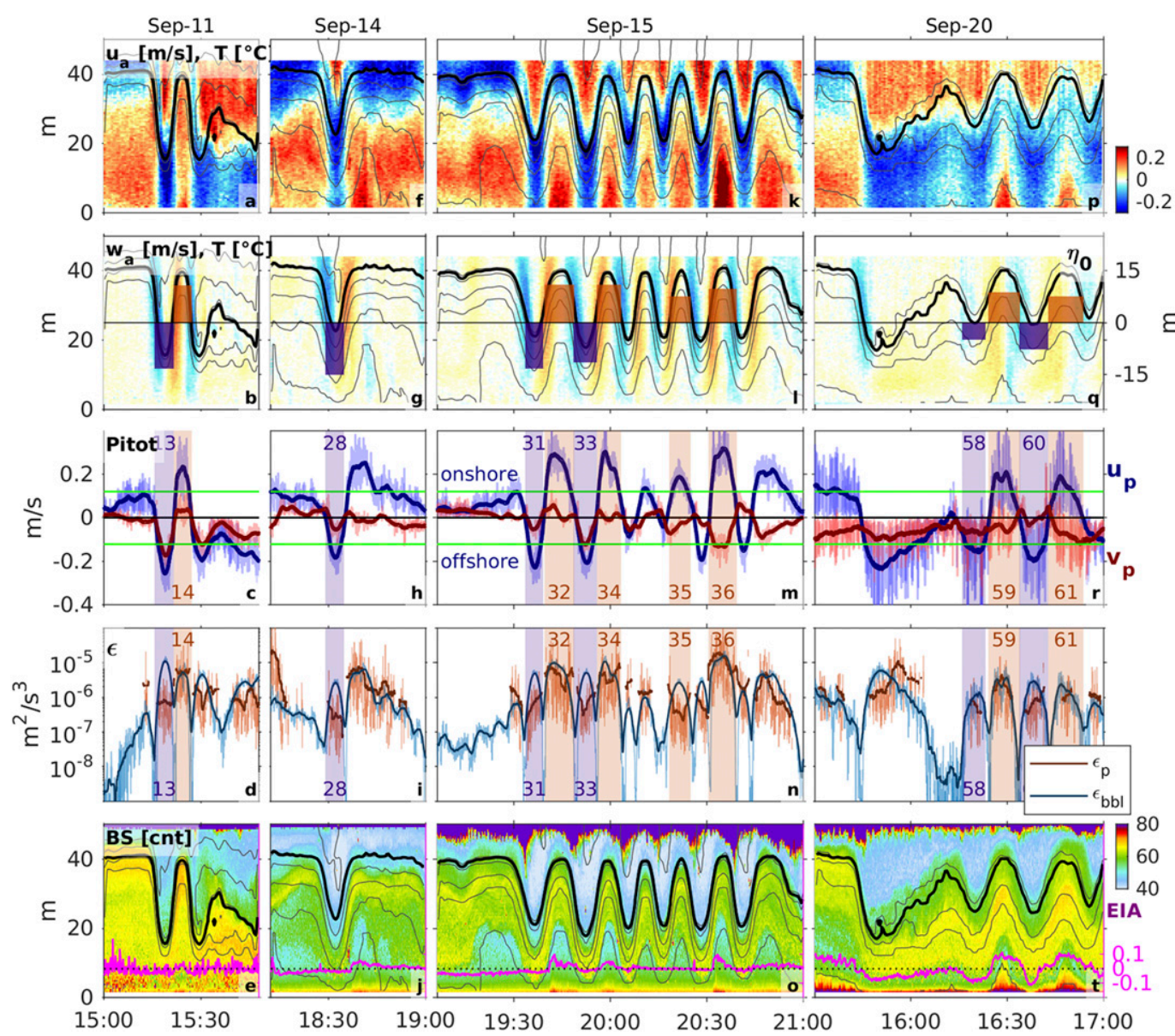

FIG. 4. Groups of high-frequency NLIWs (times correspond to green lines in Fig. 5). (a) Image plot of onshore velocity component $u_{a}$ and isotherms (gray contours; $12^{\circ}-19^{\circ} \mathrm{C}$ ). (b) Image plot of vertical velocity component $w_{a}$ and maximum isopycnal displacement of NLIWs $\eta_{0}$ associated with bottom pulse events (purple: offshore, orange: onshore). (c) Onshore $u_{p}$ (blue) and alongshore $v_{p}$ (red) components derived from pitot-static tube speed measurements (light color 100-Hz sampling rate, dark thick lines 30-s averages). (d) Dissipation rate of TKE from BBL scaling $\varepsilon_{\mathrm{bbl}}$ (blue) and pitot-static tube $\varepsilon_{p}$ (red). (e) Backscatter intensity as measured by the ADCP (color) and EIA (magenta). The thick black lines in rows (a), (b), and (e) highlight the pycnocline. The shaded background in rows (c) and (d) marks onshore (orange) and offshore (purple) bottom pulses detected by the algorithm defined in section 4c. The green line in (c) marks the threshold value, corresponding to point 2 of the pulse-detection algorithm (section 4c).

where $\eta_{0}<0\left(\eta_{0}>0\right)$ corresponds to depressions (elevations) of the pycnocline (see Fig. 4b).

We estimate the linear long wave phase speed (see, e.g., Gill 2016) as

$$
c=\sqrt{g^{\prime} \frac{h_{\mathrm{pc}}\left(H-h_{\mathrm{pc}}\right)}{H}},
$$

where $H$ is the water depth, $h_{\mathrm{pc}}$ is the height of the pycnocline at rest above the bottom, $g^{\prime}=g\left(\Delta \rho / \rho_{0}\right)$ is the reduced gravitational acceleration, $g=9.81 \mathrm{~m} \mathrm{~s}^{-2}, \rho_{0}=$ $1025 \mathrm{~kg} \mathrm{~m}^{-3}$ is the reference density, and $\Delta \rho$ is the density difference across the pycnocline.

To make use of (5), we must determine the two parameters $h_{\mathrm{pc}}$ and $\Delta \rho$ for each pulse. This is, however, not as straightforward as it might seem at first glance. The major problem is that the pycnocline is constantly modulated by the internal waves, which makes it difficult in practice to determine $h_{\mathrm{pc}}$ and $\Delta \rho$ for any given wave event, and especially challenging for long wave trains. Since most of the detected events are related to such trains, it is necessary to carefully choose the algorithms to determine $h_{\mathrm{pc}}$ and $\Delta \rho$. To accomplish this we developed the following procedure: 1 ) temperature data were low-pass filtered (120-s cutoff) to remove highfrequency fluctuations; 2) the vertical maximum in stratification was defined to set the instantaneous height of the pycnocline $\left.h_{\mathrm{pc}}(t) ; 3\right)$ the value of $h_{\mathrm{pc}}(t)$ at the leading edge of each event was chosen as the characteristic $h_{\mathrm{pc}}$; 4) $\Delta \rho$ was then determined as the difference 

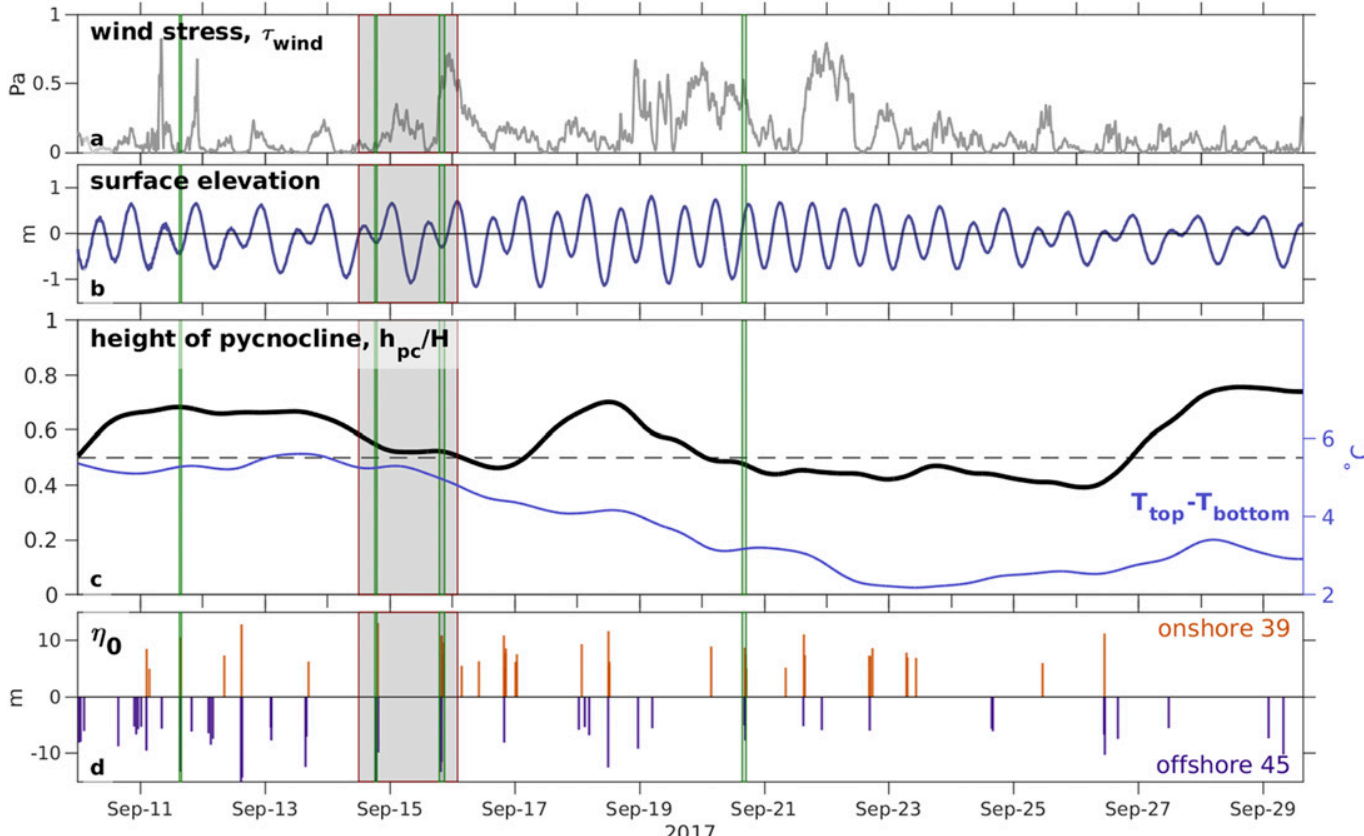

FIG. 5. Environmental conditions for the time period discussed in this manuscript. (a) Wind stress. (b) Surface elevation (Ppod data). (c) Normalized height of the pycnocline (black) and the top to bottom temperature difference in blue. (d) Maximum isopycnal displacement of NLIWs associated with bottom pulses (purple: offshore, orange: onshore). Data in (b) and (c) are low-pass filtered at a 30-min period. The shaded areas correspond to Fig. 6 (red) and green lines to Fig. 4.

between the vertically averaged density below and above the pycnocline.

From $h_{\mathrm{pc}}$ and $\Delta \rho$, we estimated the phase speed for each event using (5). Based on the measured duration of each event at the mooring location $T_{p}$ and $c$, we estimated the event length, $L=c T_{p}$.

The two-layer approximation (5) provides only a rough approximation of the true phase speed. However, more sophisticated methods based on continuous stratification and shear, come with additional complications. McSweeney et al. (2020) provide a detailed comparison of different methods to calculate $c$ covering the same dataset as ours. The results of their calculations are not significantly different from ours given the ambiguities that accompany the determination of the correct background state. Since here we only use $c$ to convert time to space, it seems sufficient to use (5).

\section{c. Pulse detection}

Near-bottom velocity measurements from the pitotstatic tube on the GusT are used to detect and classify relevant bottom pulses. The onshore-directed velocity component $u_{p}$ was first low-pass filtered with a 30-s cutoff to remove surface waves (dark blue line in Fig. 4c). All peaks (positive and negative) were identified in $u_{p}$ that are at least $120 \mathrm{~s}$ apart and with amplitude exceeding $0.12 \mathrm{~m} \mathrm{~s}^{-1}$ (green line in Fig. 4c). The change in sign of $u_{p}$ in the neighborhood of each peak marked the beginning and end of each pulse. To focus on energetically significant events, we disregard all pulses with maximum displacement $\left|\eta_{0}\right|<5 \mathrm{~m}$ and have a mean near-bottom speed $\left\langle s_{p}\right\rangle<0.1 \mathrm{~m} \mathrm{~s}^{-1}$, where $\langle\cdot\rangle$ denotes an average over the duration of a pulse.

This method excludes pulses that are either too weak, too short, or too long. The method is purposefully designed to exclude nonoscillating bore fronts (e.g., Fig. $4 r)$, very brief pulses $(<120$ s, e.g., Fig. $4 \mathrm{~m}$, before and after pulse 36 ), pulses that are not connected to a significant pycnocline displacement (e.g., Fig. 4h, after pulse 28), and pulses with small mean kinetic energy in the BBL (e.g., Fig. 4m, between pulses 34 and 35).

\section{Results}

In this section, we briefly review the general wind and ocean conditions as well as the timing and structure of the internal tide during our period of continuous, detailed observation at OC50. We then review the statistics of near-bottom pulses revealed by our pulse-detection algorithm and the accompanying BBL turbulence and acoustic backscatter intensities sensed by the ADCP. Results are summarized in normalized phase space, 


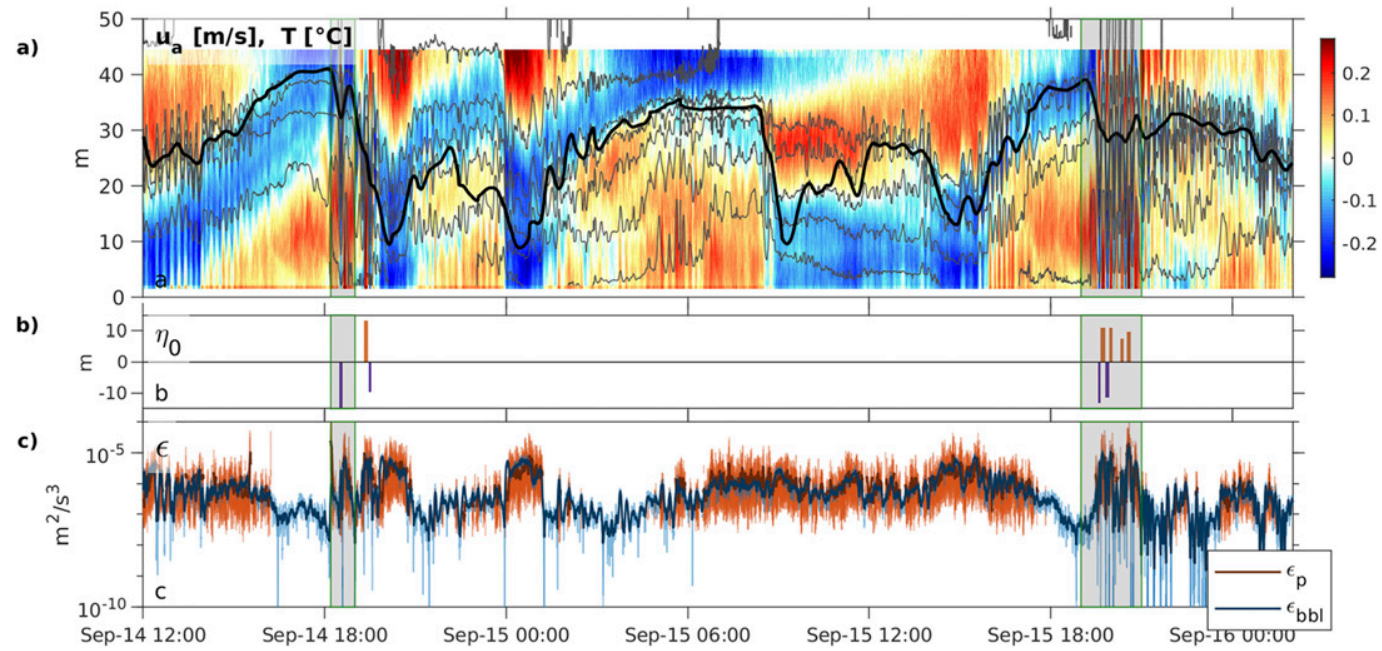

FIG. 6. Expanded detail of the gray-shaded patch in Fig. 5. (a) Onshore velocity component (color), isotherms $\left(12^{\circ}-19^{\circ} \mathrm{C} ; 1^{\circ} \mathrm{C}\right.$ increment; gray), and height of the pycnocline (black). (b) Maximum isopycnal displacement of NLIWs associated with bottom pulses (purple: offshore, orange: onshore). (c) Dissipation rates of TKE (light colors are 1-s estimates and darker colors 30 -s averages). The gray shaded areas correspond to Figs. $4 \mathrm{f}$ and $4 \mathrm{k}$.

where time is normalized by the duration of each pulse to allow for a direct comparison of all pulses.

\section{a. General conditions}

The wind conditions (Fig. 5a) during the initial five days (10-16 September) and the final six days of our observation window (23-30 September) were calm, separated by a week of moderate winds (16-23 September).

The subtidal vertical stratification $\left(T_{\text {top }}-T_{\text {bottom, }}\right.$, blue line in Fig. 5c) changed significantly during the experiment. The initial five days were characterized by relatively strong stratification with top to bottom temperature difference of up to $6^{\circ} \mathrm{C}$. During the windier period, the stratification slowly decreases to reach slightly more than $2^{\circ} \mathrm{C}$ top-to-bottom temperature difference right after the strongest wind event on the 22 September. Note that the wind forcing on 22 September not only decreased the temperature in the upper layer, but also near the bottom, suggesting upwelling (not shown). During the relaxation after the 26 September $T_{\text {top }}-T_{\text {bottom }}$ stabilized and even slightly increased to about $3^{\circ} \mathrm{C}$ toward the end of the observation period.

\section{b. Internal tide}

The onshore-directed velocity component (Fig. 6a) and the height of the pycnocline were dominated by oscillations caused by the internal tide. The internal tide appears in the form of borelike events. These bores irregularly occurred every $3-12 \mathrm{~h}$ with velocity amplitude of up to $0.3 \mathrm{~m} \mathrm{~s}^{-1}$ and greater (McSweeney et al. 2020). These bores do not appear to be phase locked to the barotropic tide (McSweeney et al. 2020), potentially suggesting a nonlocal generation of the internal tide (Nash et al. 2012). This is supported by a recent modeling study of the experiment region, which predicts the major generation sites for this area to be $O(100) \mathrm{km}$ offshore (Kumar et al. 2019).

The sea surface displacement due to the barotropic tide is illustrated in the Fig. 5b. While our 19-day observation window covers a full neap-spring cycle, the change in tidal amplitude is difficult to identify from Fig. 5b, which shows a superposition of diurnal and semidiurnal tidal components. Roughly speaking, we find neap conditions at the beginning and end of the observation period and spring conditions in the middle.

The nature of the internal bores that accompanied the internal tide varied widely, from plane rectangular shaped bore fronts to complicated undular bore types (Fig. 6a; see also McSweeney et al. 2020).

\section{c. Statistics of bottom pulses}

During the 19-day observation period, our pulsedetection scheme found a total of 84 relevant bottompulse events at this single mooring location, almost evenly divided between onshore (39) and offshore (45) pulses (Fig. 7).

Although opposite in sign, the median isopycnal displacement associated with onshore pulses is comparable in magnitude to offshore pulses (Fig. 7a). The median duration of onshore pulses $(\approx 500 \mathrm{~s})$ is larger than that of offshore pulses $(\approx 430 \mathrm{~s})$, the difference not being significant (Fig. 7c). This translates into median event lengths of $75 \mathrm{~m}$ for onshore and $65 \mathrm{~m}$ for offshore pulses 

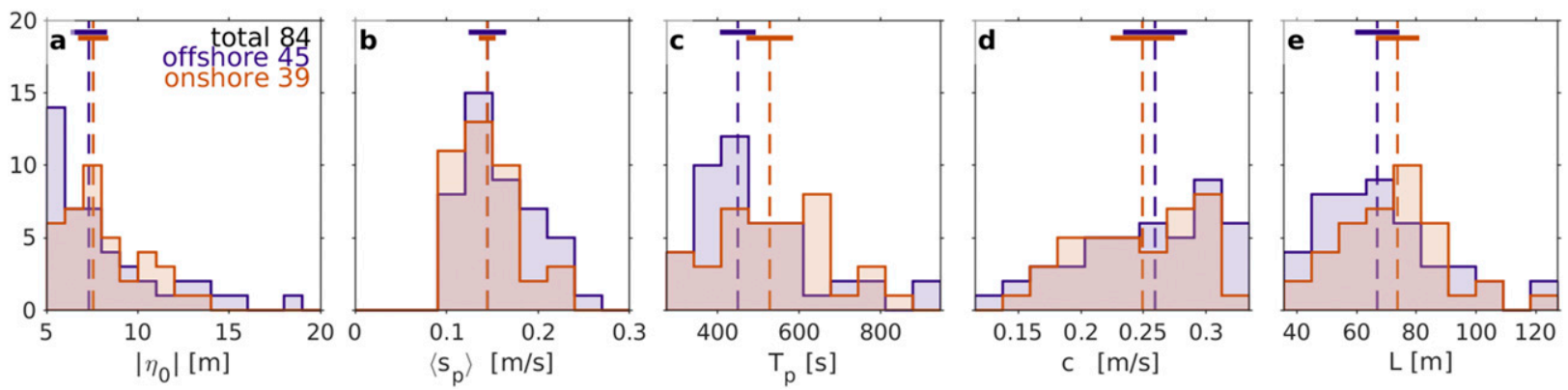

FIG. 7. Histograms of pulse statistics. (a) Maximum isopycnal displacements of associated NLIWs. (b) Mean pulse speeds. (c) Event durations. (d) Linear wave phase speed. (e) Event length $L=c T_{p}$. Dashed vertical lines indicate median values, and horizontal bars are the corresponding $95 \%$ bootstrap confidence interval.

(Fig. 7e). The median linear phase speed for both groups is comparable, $c \approx 0.25 \mathrm{~m} \mathrm{~s}^{-1}$ (Fig. $7 \mathrm{~d}$ ).

\section{d. Dissipation}

To avoid signal contamination due to the actions of surface waves, our flagging eliminated all data with mean speeds $<0.1 \mathrm{~m} \mathrm{~s}^{-1}$. The result of the flagging is seen in Fig. 6c, a 30-h comparison of $\varepsilon_{p}$ and $\varepsilon_{\mathrm{BBL}}$. Estimates of $\varepsilon_{p}$ are shown only where currents are large enough, which generally includes the internal bore events. The speed threshold used here is roughly equivalent [via Eq. (1)] to an effective lower limit $\varepsilon_{\mathrm{bbl}}=3 \times 10^{-7} \mathrm{~m}^{2} \mathrm{~s}^{-3}$.

Via Eq. (2) $\varepsilon_{\text {bbl }}$ requires an estimate of $C_{D}(z=$ $1.25 \mathrm{~m})$. The value of $C_{D}$ is selected so that $\overline{\varepsilon_{p}}=\overline{\varepsilon_{\mathrm{BBL}}}$, where the overbar denotes the averages over all data pairs (60-s averages, Fig. 8b). This results in a value of $C_{D}(z=1.25 \mathrm{~m})$ that is comparable to independent estimates based on velocity profiles at the same site in 2015 (Table 1; Allen et al. 2018). The roughness length, as estimated from Eq. (3), is $1.2 \mathrm{~mm}$, again close to that found by Allen et al. (2018).

While direct comparison of $\varepsilon_{p}$ and $\varepsilon_{\mathrm{bbl}}$ (Fig. 8) indicates a high correlation of the bulk of the data, systematic deviations appear in Fig. 4. Individual scaled values $\left(\varepsilon_{\mathrm{BBL}}\right)$ can be significantly greater than measured values $\left(\varepsilon_{p}\right)$, in particular at the leading edges of offshore pulses (Figs. 4d,i,n,s; e.g., events: 13, 31, 33, $60)$. During onshore pulses in Fig. $4, \varepsilon_{p}$ and $\varepsilon_{\mathrm{BBL}}$ deviate less and there are occurrences when $\varepsilon_{p}$ exceeds $\varepsilon_{\text {bbl }}$ (see, e.g., events: 14 and 36).

To further examine whether these few examples represent systematic differences in the way on- and offshore pulses influence BBL turbulence, we proceed with a statistical analysis of the entire record, beginning with comparisons sorted by averaged pulse velocity $\left\langle u_{p}\right\rangle$.

The term $\left\langle s_{p}\right\rangle^{2}$ can be thought of as a proxy for production of TKE in the BBL. The median value of $\left\langle s_{p}\right\rangle$ for offshore pulses is not significantly different from that of onshore pulses (Fig. 7b). This implies that both groups should have a comparable potential to generate $\mathrm{BBL}$ turbulence.

However, distributions of $\varepsilon_{p}$ differ significantly between onshore and offshore pulses (Fig. 9a). A Kolmogorov-Smirnov test comparing the distributions confirms their statistical difference. A typical onshore pulse dissipates more energy in the BBL than a corresponding offshore pulse, despite similar kinetic energy levels in the near-bottom flow. This is illustrated in Fig. 9b, showing ratios of $\left\langle\varepsilon_{p}\right\rangle /\left\langle\varepsilon_{\mathrm{bbl}}\right\rangle$. We find that the median offshore pulse yields significantly smaller values of $\left\langle\varepsilon_{p}\right\rangle$ than expected from the law of the wall while onshore pulses exhibit insignificantly larger values of $\left\langle\varepsilon_{p}\right\rangle$ than the law of the wall.

We now compare features of the general structures of onshore and offshore pulses by first nondimensionalizing each pulse in time relative to its initial arrival $t_{0}$ and total duration $T_{p}$ and then averaging over all offshore and all onshore pulses. The nondimensional time axis in Fig. 10, $t_{*}=\left(t-t_{0}\right) / T_{p}$, represents a shared phase (or nondimensional time) axis for all pulses. Data were then binned into 50 equally spaced phase bins and median values computed for each bin, represented by the orange and purple lines in Fig. 10.

There is a level of imprecision in identifying pulse leading and trailing edges from $u_{p}$ using the method described in section $4 \mathrm{c}$ because of variations in the background flow, and hence $|\eta|$ at $t_{*}=0$ and $t_{*}=1$ is not necessarily equal to zero in (Fig. 10a). The normalized phase structure of $|\eta|$ indicates that positive values associated with onshore pulses are indistinct (aside from sign) from the negative values associated with offshore pulses (Fig. 10a). This suggests that there is no obvious asymmetry in $|\eta|$ between pulses of opposite sign. The same is true for the across-shore velocity component, where $s_{p}$ during onshore pulses does not differ from the corresponding offshore pulses (not shown).

The direct measurements of $\varepsilon_{p}$, however, indicate asymmetries in the turbulence throughout the pulse and 

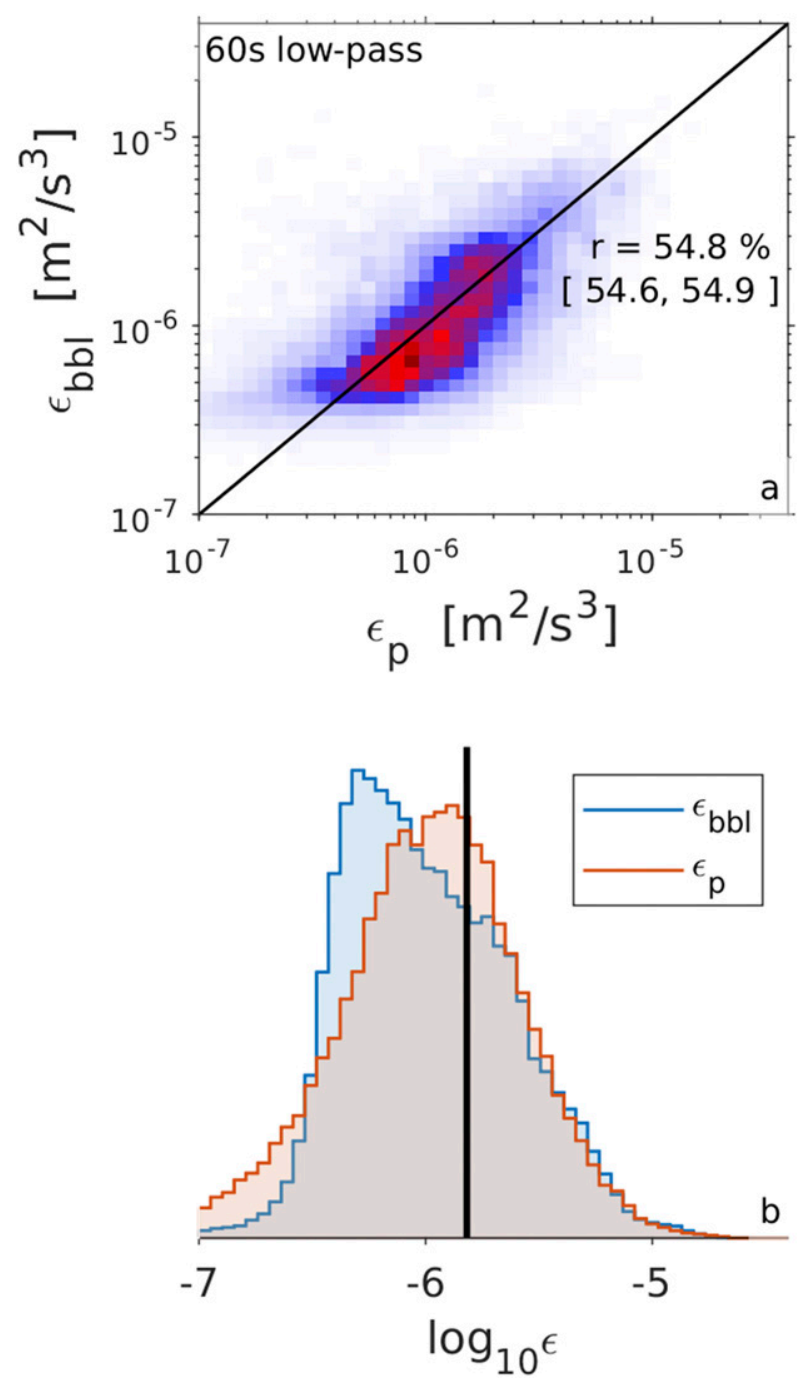

FIG. 8. Comparison of $\varepsilon_{p}$ to the law of the wall. (a) 2D histogram comparing $\varepsilon_{p}$ and $\varepsilon_{\mathrm{bbl}}$. Both estimates are using pitot tube measurements, where $\varepsilon_{p}$ is based on a spectral fit (see the appendix) and $\varepsilon_{\text {bbl }}$ on a scaling [Eq. (1)] that employs the 60-s averaged speed $s_{p}$. (b) Probability distributions of $\log _{10} \varepsilon_{p}$ and $\log _{10} \varepsilon_{\mathrm{bbl}} . C_{D}=3.3 \times$ $10^{-3}$ in Eq. (2) is chosen such that $\overline{\varepsilon_{\mathrm{bbl}}}=\overline{\varepsilon_{p}}$, as indicated by the black line in (b).

between onshore and offshore pulses. The onshore pulse distribution of $\varepsilon_{p}$ tends to significantly larger values and the median is 3 times larger than that for offshore pulses (Fig. 9a).

In this phase-averaged view, we first normalize $\varepsilon_{p}$ by the event-averaged dissipation rate obtained from BBL scaling $\left\langle\varepsilon_{\mathrm{BBL}}\right\rangle$ before all pulses are averaged together in normalized phase (Fig. 10b). This step is key to a statistical depiction of the evolution of $\varepsilon_{p}$ across an average pulse, since without normalization the phase-averaged value would be dominated by a very few energetic events. The onshore pulse in Fig. $10 \mathrm{~b}$ shows $\varepsilon_{p}$ to be
TABLE 1. Comparison of depth-dependent drag coefficients together with estimated bottom roughness lengths. The bottom slopes for three regions are also noted. The differing bottom slopes off Point Sal are from different locations. The Allen et al. (2018) measurements were made south of the location of OC50 over steeper topography.

\begin{tabular}{lcccc}
\hline \hline \multicolumn{1}{c}{ Location } & $z(\mathrm{~m})$ & $\begin{array}{c}C_{d} \\
\left(10^{-3}\right)\end{array}$ & $\begin{array}{c}z_{0} \\
\left(10^{-3} \mathrm{~m}\right)\end{array}$ & $\begin{array}{c}\text { Bottom } \\
\text { slope }\left(10^{-3}\right)\end{array}$ \\
\hline $\begin{array}{l}\text { Oregon shelf (Perlin } \\
\text { et al. 2005) }\end{array}$ & 20 & 1.0 & 0.08 & 3.6 \\
$\begin{array}{c}\text { Australian Shelf } \\
\quad \text { Zulberti et al. 2018) }\end{array}$ & 0.49 & 1.5 & 0.15 & \\
$\begin{array}{c}\text { Point Sal (CA) (Allen } \\
\text { et al. 2018) }\end{array}$ & 1 & 3.8 & 1.5 & $7.0-8.7$ \\
$\begin{array}{c}\text { Present study (OC50) } \\
\text { (O) }\end{array}$ & 1.25 & 3.3 & 1.2 & 5.5 \\
\hline
\end{tabular}

constant over $0.1<t_{*}<0.7$ where it is indistinct from the pulse-averaged value $\left\langle\varepsilon_{\mathrm{BBL}}\right\rangle$ and decreasing toward leading and trailing edges. Contrasting this is the normalized phase structure of $\varepsilon_{p}$ through offshore pulses, which is significantly smaller than $\left\langle\varepsilon_{\mathrm{BBL}}\right\rangle$, particularly toward the leading edge of the pulses. Despite $s_{p}$ and thus $\varepsilon_{\mathrm{bbl}}$ decreasing at $0.5<t_{*}<1, \varepsilon_{p}$ increases between $0.5<t_{*}<0.8$, pointing toward an asymmetry between leading and trailing phase of offshore pulses.

\section{e. Sediment}

Near-bottom turbulence acts to scour seafloor sediments and raise them into suspension above the bed. The sediment concentration was not measured directly during the experiment. However, bottom samples taken at several locations in the area reveal a tight grain size distribution around $100 \mu \mathrm{m}$ of sand (R. Mieras and J. Calantoni 2019, personal communication). Suspended in the water column, these sediments are acoustically sensed by the bottom-mounted ADCP at $500-\mathrm{kHz}$ center frequency (see, e.g., Holdaway et al. 1999). To gain qualitative insight into the changing sediment concentration in the BBL, we calculate the echo intensity anomaly (EIA) from uncalibrated ADCP acoustic backscatter intensity. To this end, the instantaneous backscatter value at each of the lowest three bins (1.25$2.75 \mathrm{~m}$ above the bed) is divided by its median value over the entire measurement period. After bandpass filtering $(1-30 \mathrm{~min})$ the lowest three bins are averaged together to obtain a value of EIA representative of the BBL.

Through offshore pulses EIA is near zero, the median value being slightly; smaller than zero (Figs. 10c and 11). This implies that offshore pulses are associated with slightly lower sediment concentrations than average values in the BBL. Onshore pulses exhibit significantly increased echo intensities. The median over all onshore 


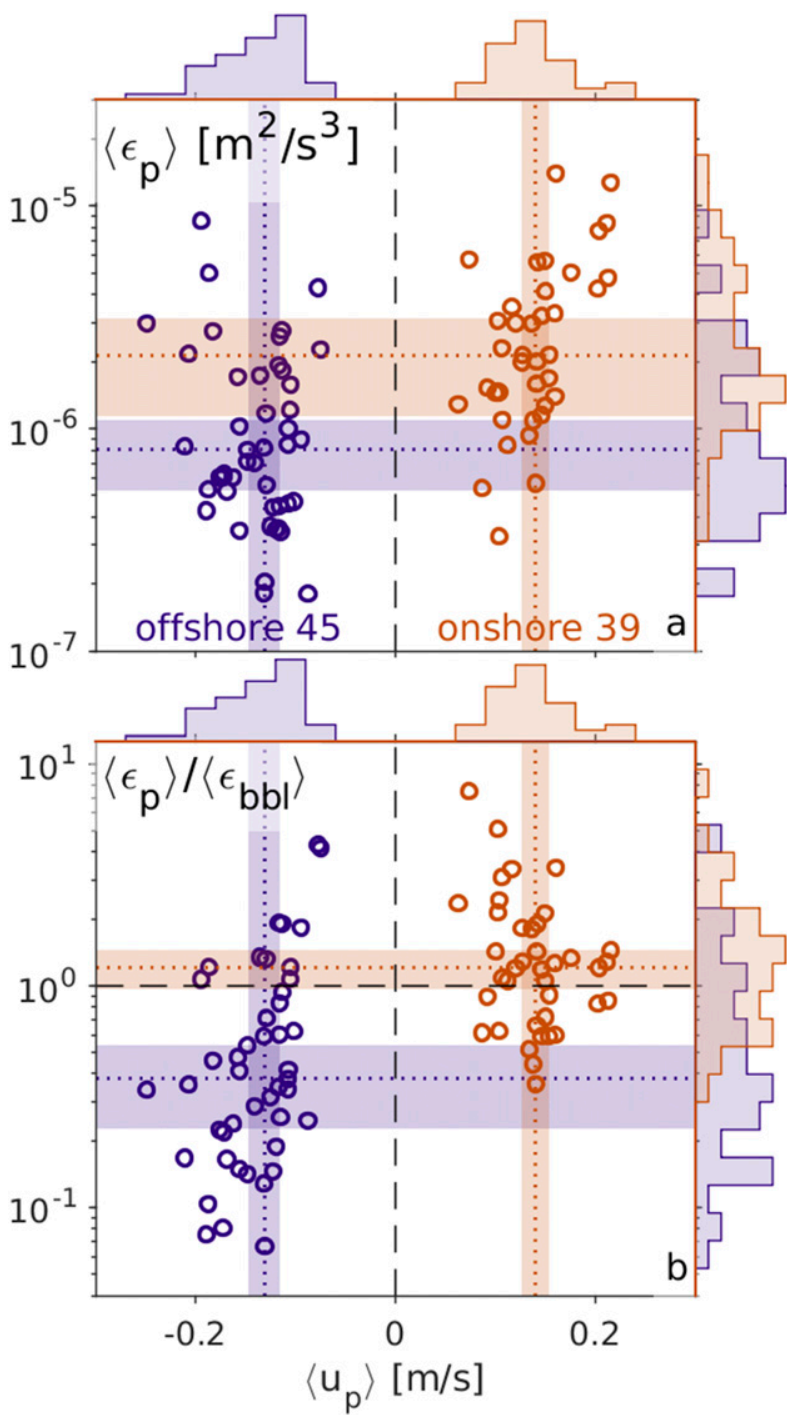

FIG. 9. Scatterplot of pulse averaged dissipation rates vs $\left\langle u_{p}\right\rangle$. (a) Dissipation rates measured by the pitot tube $\left\langle\varepsilon_{p}\right\rangle$, and (b) $\left\langle\varepsilon_{p}\right\rangle$ normalized by event averaged BBL scaling $\left\langle\varepsilon_{\mathrm{bbl}}\right\rangle$. Dotted lines indicate median values for each distribution on top and on the side of each panel, and the color shaded background indicates the $95 \%$ bootstrap confidence interval.

pulses is clearly larger than zero, where the strongest bottom pulses are also associated with the largest anomalies (Fig. 11). This implies that the stronger the onshore pulse, the more sediment it carries-a finding that agrees with earlier observations by Bogucki et al. (1997). This is not the case for offshore pulses.

The normalized phase structure of EIA (Fig. 10c) is relatively flat through offshore pulses, implying that the sediment concentration does not change through the pulse. For onshore pulses, EIA is elevated at the leading edge (Fig. 10c) and increases during the early stage of the pulse to a peak value ahead of the maximum $s_{p}\left(t_{*} \approx 0.5\right)$. EIA decreases following the peak but remains clearly above ambient values throughout the duration of the onshore pulse. The slightly asymmetric timing of EIA for onshore pulses coincides with a corresponding asymmetry in $\varepsilon_{p}$ (cf. Figs. $10 \mathrm{~b}, \mathrm{c}$ ).

\section{Discussion}

Our measurements suggest general asymmetries in BBL turbulence between onshore and offshore pulses as well as detailed asymmetries in the structure throughout the pulses themselves in terms of their normalized phase. We summarize these asymmetries here and then examine fluid dynamical explanations.

Two significant asymmetries appear between on/offshore pulses. The significantly greater values of $\left\langle\varepsilon_{p}\right\rangle$ in onshore pulses that are $\approx \varepsilon_{\mathrm{BBL}}$ throughout most of the pulse is clear in Figs. 9 and $10 \mathrm{~b} ;\left\langle\varepsilon_{p}\right\rangle$ is generally significantly less than $\varepsilon_{\mathrm{BBL}}$ in offshore pulses. Additionally (and possibly related), onshore pulses exhibit greater acoustic backscatter intensities, presumably due to increased sediment load above the bed (Figs. 10c and 11).

A minor asymmetry appears in the structure of $\varepsilon_{p}$ through onshore pulses (Fig. 10b). The $\varepsilon_{p}$ increases rapidly from the leading edge to asymptote to $\varepsilon_{\mathrm{BBL}}$ at $t_{*} \approx 0.05$ but decreases from that value at $t_{*} \approx 0.75$, leading to a normalized phase distribution of $\varepsilon_{p}$ that is skewed toward the leading edge of onshore pulses.

A more significant asymmetry appears in the structure of $\varepsilon_{p}$ through offshore pulses. In this case, $\varepsilon_{p}$ is generally (and significantly) smaller than $\varepsilon_{\mathrm{BBL}}$, increasing toward the trailing edge and decreasing beyond $t_{*} \approx 0.9$. In this case, the normalized phase distribution of $\varepsilon_{p}$ is skewed toward the trailing edge of the pulses.

These observed asymmetries in the nature of the turbulence coexist with structural differences between on- and offshore pulses. These include the seafloor pressure distribution through the pulse, the residence time of a fluid parcel in the pulse and the potential for turbulence suppression by stratification. These differences are discussed in the following three subsections.

\section{a. The seafloor pressure distribution and implications for instability}

The NLIW seafloor pressure is comprised of a nonhydrostatic component $P_{\mathrm{nh}}$, an internal hydrostatic component $P_{h}$, and a surface component (Moum and Smyth 2006). The internal hydrostatic component $P_{h}$ is calculated from the density field and $P_{\mathrm{nh}}$ from the vertical velocity field. Here, we ignore the relatively smaller surface component. Further, we consider a wave traveling without change of form, so that $\partial_{t}=-c \partial_{x}$, 

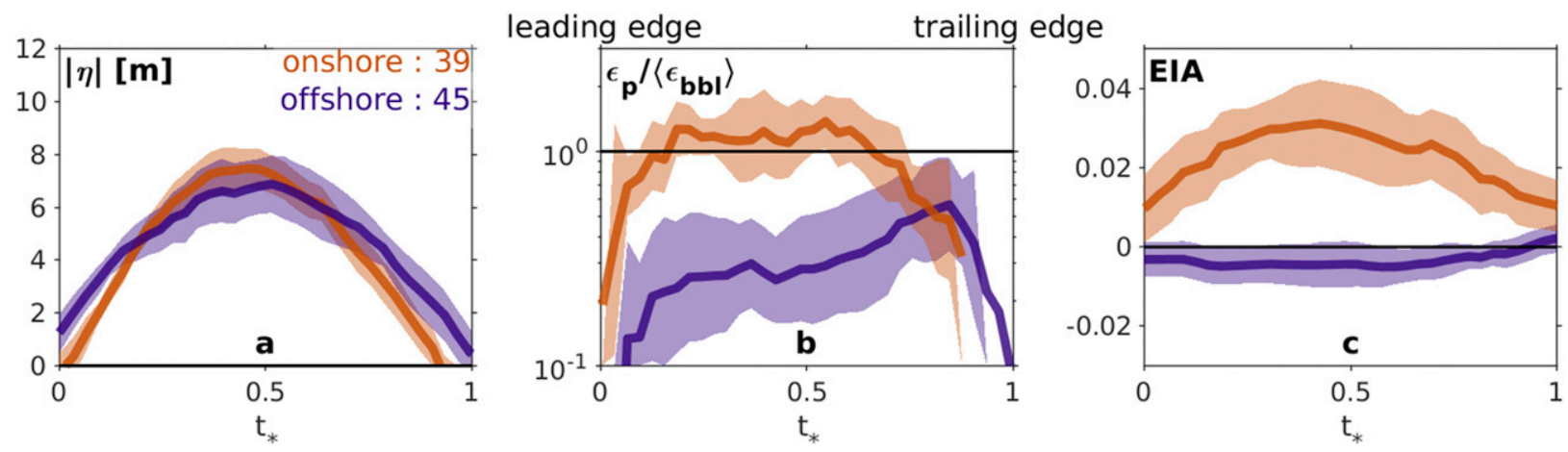

FIG. 10. Normalized phase structure of near-bottom velocity pulses. (a) Isothermal displacement magnitude $|\eta|$. (b) $\varepsilon_{p}$ normalized by the event-averaged law-of-the-wall estimate $\left\langle\varepsilon_{\mathrm{BBL}}\right\rangle$. (c) EIA. Thick orange (purple) lines show median values of all onshore (offshore) pulses. Shading represents $95 \%$ bootstrap confidence intervals on the median values. The $x$ axis shows the normalized phase, where $t_{*}=\left(t-t_{0}\right) / T_{p}=0$ or 1 corresponds to the leading and trailing edge, respectively.

where $\partial_{t}, \partial_{x}$ denote partial derivatives with respect to time and onshore direction. We estimate the pressure gradient across a pulse (see Fig. 12) as

$$
\partial_{x} P=-\frac{1}{c} \partial_{t}\left(P_{h}+P_{\mathrm{nh}}\right) .
$$

The reader is referred to Moum and Smyth (2006) for a detailed discussion of the pressure distribution and its calculation.

Ignoring rotation as well as vertical and along-shelf advection the across-shelf momentum balance in direction of wave propagation

$$
\partial_{t} u+u \partial_{x} u-\partial_{z}\left(K_{v}+\nu\right) \partial_{z} u=-\frac{\partial_{x} P}{\rho_{0}}
$$

where $K_{v}$ and $\nu$ are turbulent and molecular viscosities, respectively. Alternatively,

$$
(u-c) \partial_{x} u-\partial_{z}\left(K_{v}+\nu\right) \partial_{z} u=-\frac{\partial_{x} P}{\rho_{0}} .
$$

The velocity $u$ must go to 0 at $z=0$ and match the velocity outside the boundary layer, $u=u_{w}+u_{\mathrm{bg}}$, where $u_{\mathrm{bg}}$ denotes a background flow and $u_{w}$ the flow generated due to the pressure disturbance.

Near the seafloor, $\partial_{x} u$ goes to 0 and inside of the constant stress layer $\partial_{z}\left(K_{v} \partial_{z} u\right)$. Hence,

$$
\partial_{z z}^{2} u \simeq \frac{\partial_{x} P}{\nu \rho_{0}} .
$$

Away from the seafloor, $\partial_{z z}^{2} u$ diminishes (see Figs. 13kn) and

$$
(u-c) \partial_{x} u \simeq-\frac{\partial_{x} P}{\rho_{0}} .
$$

Since $(u-c)<0, \operatorname{sgn}\left(\partial_{x} P\right)=\operatorname{sgn}\left(\partial_{x} u\right)$ as is represented in Figs. 13a-j for onshore and offshore pulses propagating along the seafloor into zero (Figs. 13e,f), opposing (Figs. 13g,h), and assisting (Figs. 13i,j) background flows.

The condition for shear instability in unstratified flow is an inflection point in the velocity profile (Smyth and Carpenter 2019). The four cases shown in Figs. 13k-n illustrate the general condition for the occurrence of an inflection point in the velocity profile, that $u$ and $\partial_{z z}^{2} u$ have the same sign near to the seafloor. From (9) this is equivalent to $u \partial_{x} P>0$. Figures $13 \mathrm{~m}$ and $13 \mathrm{n}$ illustrate the case of an adverse pressure gradient, where the flow opposes the pressure gradient (Schlichting and Gersten 2016). The

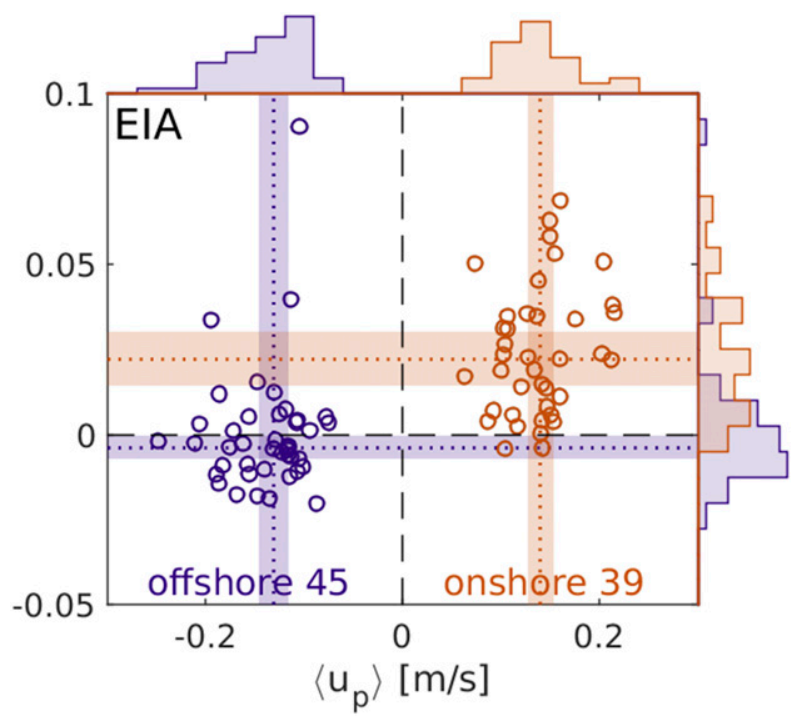

FIG. 11. EIA vs $\left\langle u_{p}\right\rangle$. Orange (purple) circles show onshore (offshore) pulses. Dotted lines illustrate median values of each group of pulses, where patches correspond to $95 \%$ bootstrap confidence intervals. 


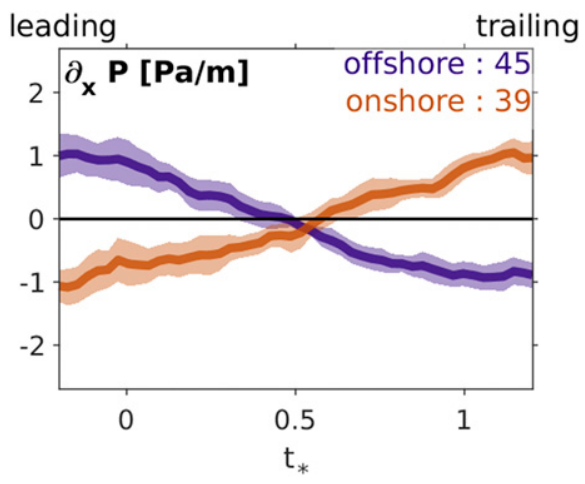

FIG. 12. Normalized phase structure of horizontal pressure gradient $\partial_{x} P$ for on shore (offshore) pulses in orange (purple) based on (6).

case of the favorable pressure gradient, $u \partial_{x} P<0$, is stable (Figs. 13k,1).

Adverse pressure gradients are shown in the trailing edges of both on- and offshore pulses propagating into $u_{\mathrm{bg}}=0$ (Figs. 13e,f). The presence of opposing and assisting background flows can create adverse pressure gradients in on- and offshore pulses, respectively (Figs. 13h,i), as denoted by $\operatorname{sgn}\left(u \partial_{x} P\right)=1$ in Fig. 13.

It is possible that the larger averaged $\varepsilon$ found at the trailing edge of offshore pulses (Fig. 10b) is due to the greater potential for instability in that adverse pressure gradient region. It is most likely that $u_{\mathrm{bg}}$ is small except during incoming wave trains such as depicted in Fig. 4k. In this case, alternating onshore/offshore pulses propagate into opposing flows created by the preceding pulse, generating additional potential sites for instability.

Diamessis and Redekopp (2006) have shown the presence of instability (in their vernacular, global instability) in the trailing edge of depression waves while Stastna and Lamb $(2002,2008)$ recognized the importance of an opposing flow for instability at the leading edge of elevation waves. While it possible that a closer consideration of the processes of global instability (Bogucki and Redekopp 1999; Boegman and Stastna 2019) and relaminarization (Aghsaee et al. 2012; Narasimha and Sreenivasan 1973) may yield additional insight into this topic, the instability locations
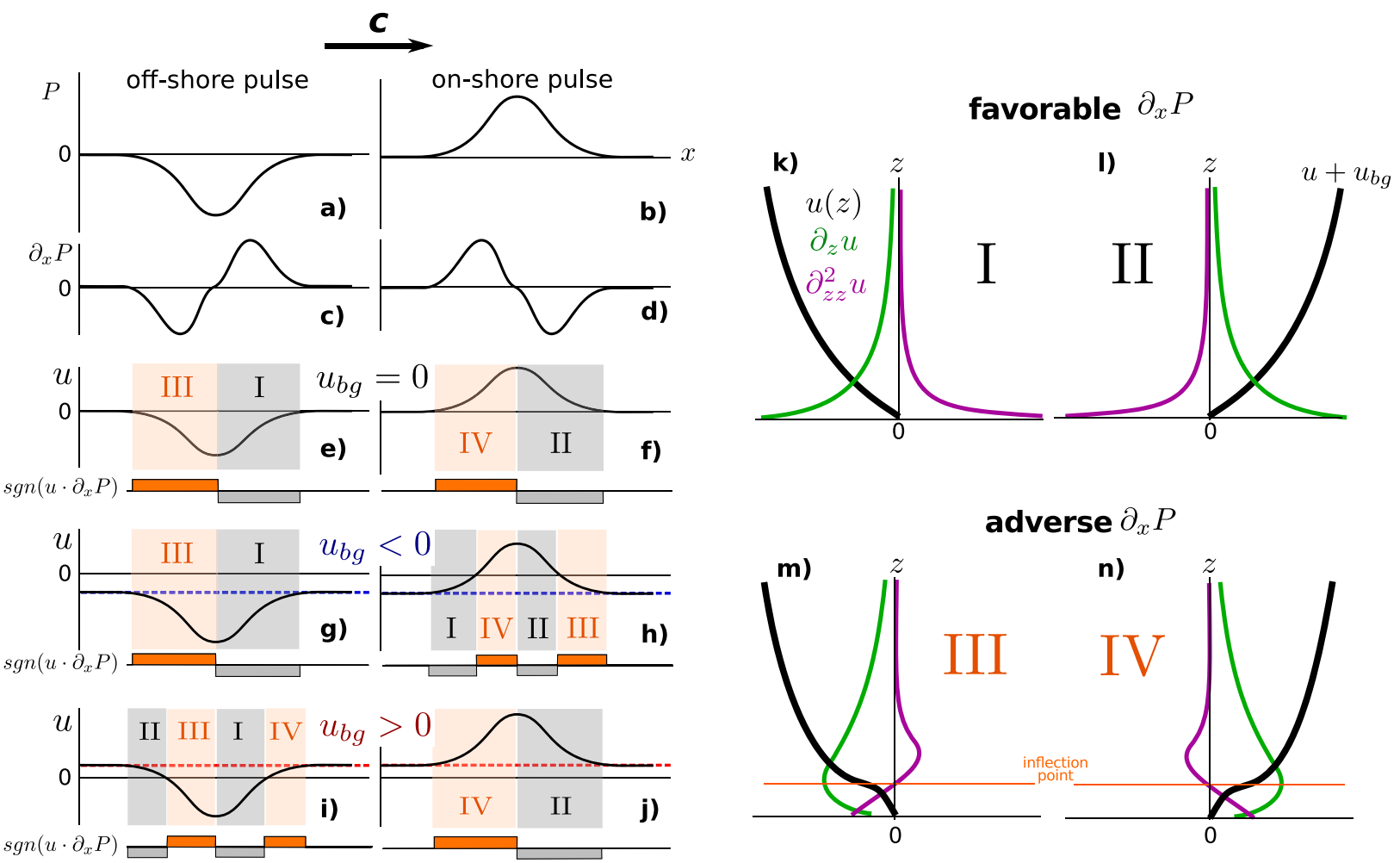

FIG. 13. Schematic showing different inflection point configurations in (a),(c),(e),(g),(i) offshore and (b),(d),(f),(h) onshore pulses. (a),(b) Horizontal distribution of pressure; (c),(d) pressure gradient; (e)-(j) free flow velocity $u=u_{w}+u_{\mathrm{bg}}$, where (e) and (f) correspond to no background flow $\left(u_{\mathrm{bg}}=0\right),(\mathrm{g})$ and $(\mathrm{h})$ correspond to opposing background flow $\left(u_{\mathrm{bg}}<0\right)$, (i) and (j) correspond to assisting background flow $\left(u_{\mathrm{bg}}>0\right)$. $(\mathrm{k})-(\mathrm{n})$ Four different cases of vertical velocity profiles (black), the corresponding shear (green), and profile curvature (purple). Cases I and III have $u<0$ and II, IV $u>0$. There is no inflection point in the vertical profiles I and II, but cases III and IV yield a near-bed inflection point. The general condition for an inflection point near the bed is $\operatorname{sgn}\left(\partial_{z} u \partial_{z z}^{2} u\right)=\operatorname{sgn}\left(u \partial_{x} P\right)=+1$. 

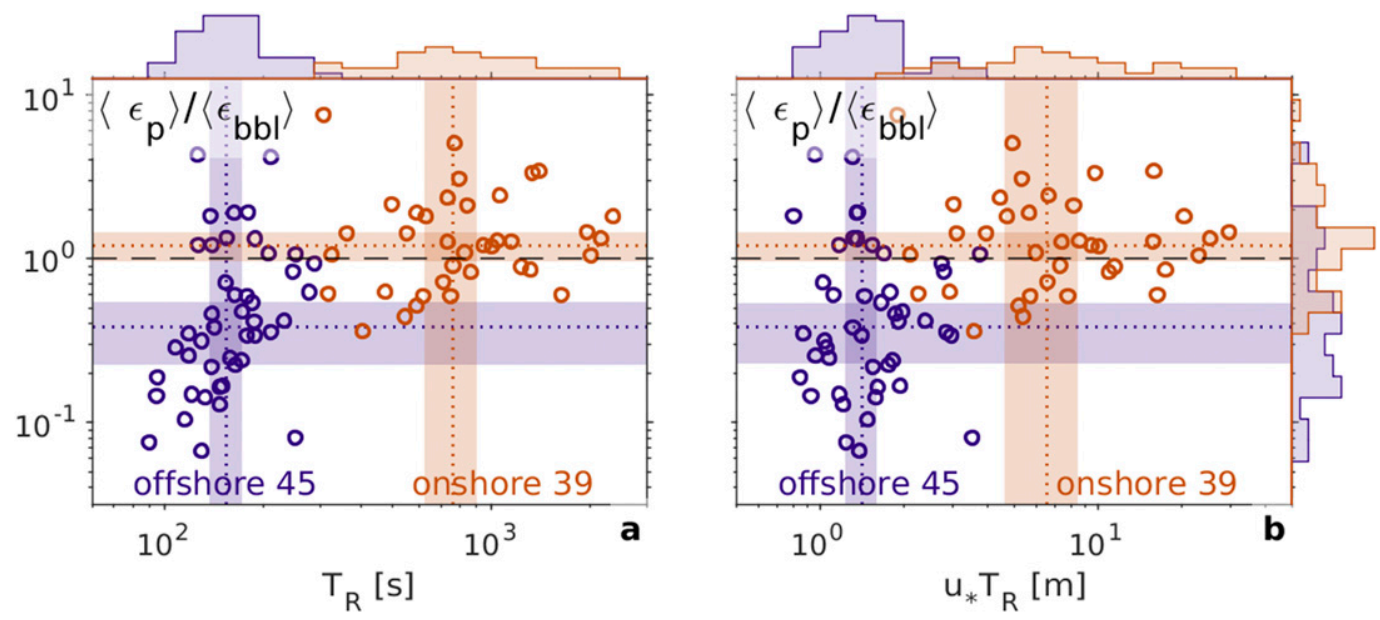

FIG. 14. (a) Residence times $T_{R}$ of fluid parcels in velocity pulses and (b) corresponding scaling for BBL height $u * T_{R}$, both vs the ratio of dissipation rates estimated by the pitot tube and BBL scaling. Dotted lines illustrate median values of each group of pulses, where patches correspond to $95 \%$ bootstrap confidence intervals.

due to inflection points in the velocity profile are indicated in basic terms in Fig. 13.

\section{b. Residence time}

On- and offshore pulses also differ in relation to the propagation direction of the associated NLIW, which always propagates onshore in our case. Therefore, velocities of onshore pulses are in the same direction and velocities of offshore pulses are in the opposite direction to the propagating NLIW. In a Lagrangian sense, a water parcel within an onshore (offshore) pulse travels with (against) the propagation direction of the wave. Consequently, fluid in an onshore pulse remains with the pulse for a longer period of time. The difference in the time of influence of the pulse on the fluid is potentially an important factor, given that neither the onset of the initial instability, the growth of the turbulent BBL, nor the generation of an equilibrium between shear production at large scales and dissipation at small scales is instantaneous.

The residence time of a fluid parcel in a pulse can be estimated by

$$
T_{R}=\frac{L}{\left(c-\left\langle u_{p}\right\rangle\right)}=\frac{c}{\left(c-\left\langle u_{p}\right\rangle\right)} T_{P} .
$$

For onshore pulses, $\left\langle u_{p}\right\rangle$ and $c$ are both $>0$ so that the denominator of (11) is small and $T_{R}$ is relatively larger than for offshore pulses, where $\left\langle u_{p}\right\rangle<0$.

Figure 14a shows a clear difference in $T_{R}$ between on- and offshore pulses, where the median residence time in onshore pulses is $800 \mathrm{~s}$ and $200 \mathrm{~s}$ in offshore pulses. Fluid parcels in near-bottom onshore pulses feel the associated bottom stresses about 4 times longer than in corresponding offshore pulses. Therefore, given bottom stresses of comparable magnitude, there is significantly shorter time to set up a turbulence cascade in the BBL in offshore compared to onshore pulses.

Another important factor in the explanation of the observed asymmetries could be the growth rate of BBL thickness. If we assume that the thickness of the BBL is related to a diffusion equation, it follows that its growth rate is proportional to $u *$ (Tennekes and Lumley 1972). Therefore, $u * T_{R}$ can be used as a proxy for BBL height increase associated with a particular bottom pulse.

For all onshore pulses $u_{*} T_{R} \gg 1 \mathrm{~m}$, which implies that the sensor at $1.25 \mathrm{~m}$ above the bed (mab) is well within the turbulent boundary layer, resulting in $\left\langle\varepsilon_{p}\right\rangle /\left\langle\varepsilon_{\mathrm{bbl}}\right\rangle \approx 1$ (Fig. 14b). Most offshore pulses on the other hand have $u * T_{R} \approx 1 \mathrm{~m}$. It is therefore not certain that the turbulent BBL is able to reach the height of GusT during the duration of an offshore pulse. The fact that $u * T_{R}$ is of the same order as our sensor height might also provide an explanation for the wide spread of $\left\langle\varepsilon_{p}\right\rangle /\left\langle\varepsilon_{\mathrm{bbl}}\right\rangle$ for offshore pulses (Fig. 14b). Depending on the preexisting condition, the sensor either lies within or outside the turbulent BBL.

The skewed phase resolved distribution of $\varepsilon_{p} /\left\langle\varepsilon_{\mathrm{bbl}}\right\rangle$ (Fig. 10b) may also be explained with the growth of the BBL thickness. Only at the end of an average offshore pulse, the BBL thickness reaches the sensor height, causing $\varepsilon_{p} /\left\langle\varepsilon_{\mathrm{bbl}}\right\rangle$ to significantly increase.

\section{c. Turbulence suppression by stratification}

Another influencing factor is vertical stratification. Perlin et al. (2005) showed that the law of the wall can be 
significantly altered in the presence of vertical stratification. To account for the suppressing influence of vertical stratification on BBL turbulence, Perlin et al. (2005) proposed a correction factor for the law of the wall based on the length scale ratio $\kappa z / L_{\mathrm{Oz}}$. While $\kappa z$ expresses the size limitation of large eddies due to proximity of the boundary, the Ozmidov scale,

$$
L_{\mathrm{Oz}}=\sqrt{\frac{\varepsilon}{N^{3}}},
$$

represents a limit to the size of the largest eddies in stratified turbulence (Gargett et al. 1984). When and where $\kappa z \geq L_{\mathrm{Oz}}$, the expectation is that stratification is a limiting factor in turbulence development.

One might expect that the more stratified regions farther from the seafloor are brought closer to the seafloor during offshore pulses (isopycnal depression) and farther away during onshore pulses (isopycnal elevation). Figure 15 a shows the vertical temperature gradient at $3 \mathrm{mab}^{3}$ The median temperature gradient at 3 mab is indeed significantly larger for offshore than for onshore pulses.

For the most part, $\kappa z \ll L_{\mathrm{Oz}}$ for our events (Fig. 15b). Only $10 \%$ of events ( 8 offshore and 1 onshore pulse) have $\kappa z / L_{\mathrm{Oz}}>0.1$, indicating that stratification is not a limiting factor. ${ }^{4}$ Even if we disregard events with $\kappa z / L_{\mathrm{Oz}}>0.1$, thus considering only events with negligible stratification influence, $\left\langle\varepsilon_{p}\right\rangle /\left\langle\varepsilon_{\mathrm{bbl}}\right\rangle$ is still significantly larger for onshore than for offshore pulses (Fig. 15b).

Consequently, we conclude that stratification is not a leading order reason for the systematic difference in $\left\langle\varepsilon_{p}\right\rangle$ between on- and offshore pulses that close to the bed.

\section{Conclusions}

In this paper, we present continuous and extended time series measurements of velocity and turbulence $1 \mathrm{~m}$ above the seafloor of the inner shelf, using a GusT turbulence/speed probe. Because the GusT speed measurements are sampled fast $(100 \mathrm{~Hz})$ and resolve small

\footnotetext{
${ }^{3}$ The two deepest $\mathrm{T}$ loggers of the collocated $\mathrm{T}$ chain are mounted at 2 and 4 mab.

${ }^{4}$ To calculate $L_{\mathrm{Oz}}$, we used $\left\langle\varepsilon_{\mathrm{bbl}}\right\rangle$ instead of $\left\langle\varepsilon_{p}\right\rangle$ because we are only interested in the effect of stratification. Using $\left\langle\varepsilon_{p}\right\rangle$ would automatically yield a stronger distinction between on- and offshore pulses, since $\left\langle\varepsilon_{p}\right\rangle$ is already asymmetric itself. We furthermore used $N^{2}$ from 3 mab, which most likely overestimates stratification at the height of the GusT (1.25 mab) and therefore underestimates $L_{\mathrm{Oz}}$. The values of the ratio $\kappa z / L_{\mathrm{Oz}}$ presented here are consequently overestimates, which further highlights the irrelevance of stratification that close to the bed.
}
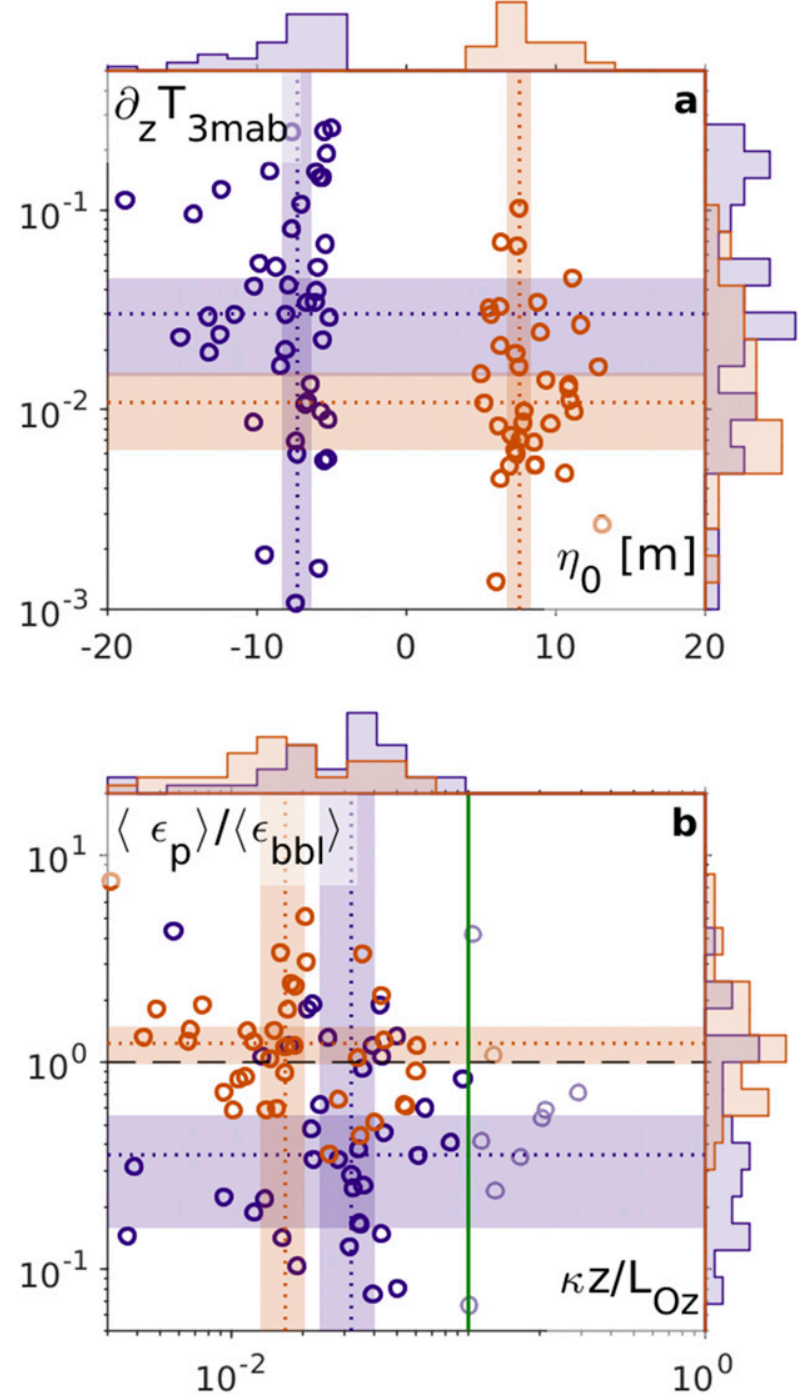

FIG. 15. (a) Maximum isopycnal displacement vs temperature stratification $\partial_{z} T$ at $3 \mathrm{~m}$ above the bed and (b) $\left\langle\varepsilon_{p}\right\rangle /\left\langle\varepsilon_{\text {bbl }}\right\rangle$ vs the length scale ratio $\kappa z / L_{\mathrm{Oz}}$. Purple corresponds to offshore (isopycnal depression) and orange to onshore (isopycnal elevation) pulses. Dotted lines illustrate median values of each group of pulses, where patches correspond to $95 \%$ bootstrap confidence intervals. In contrast to Fig. $9 \mathrm{~b}$, all data with $\kappa z / L_{\mathrm{Oz}}>0.1$ (green line) have been excluded for the median calculation in (b) so as to consider only pulses with negligible influence of stratification.

scales [roughly the diameter of the device, $O(1) \mathrm{cm}$ ], they include the inertial subrange of the turbulence, from which $\varepsilon_{p}$ is computed by scaling (appendix). We find that on longer time scales $(>10 \mathrm{~min}) \varepsilon_{p} \approx$ $\varepsilon_{\mathrm{BBL}}$. However, on shorter time scales and particularly through offshore velocity pulses associated with NLIWs of depression, we find significant deviations from BBL scaling.

We contrast near-bottom onshore pulses associated with isopycnal elevation and offshore pulses 
associated with isopycnal depression. Onshore pulses exhibit significantly greater BBL turbulence and enhanced acoustic backscatter compared to offshore pulses. In addition, the normalized phase structure through the pulses indicates turbulence skewed toward the leading edge of onshore pulses but toward the trailing edge of offshore pulses. These asymmetries suggest fundamental differences in the manner by which NLIWs interact with the seafloor.

We consider three independent mechanisms that may contribute to the observed asymmetry (section 6); propagation in adverse pressure gradients and the resultant inflection point instability, residence time of a fluid parcel in the pulses, and turbulence suppression by the stratification. The first mechanism may largely explain higher turbulence in the trailing edge of offshore pulses. The extended residence time in onshore pulses may be responsible for the high and relatively uniform turbulence distribution across the pulses. The differing vertical stratification between on- and offshore pulses in not likely the major contributor to the turbulence asymmetries in the BBL $1 \mathrm{~m}$ above the bed. However, this does not mean that stratification is not an additional source of asymmetry in the upper BBL above. It is well-established that internal-wave-induced asymmetrical stratification can result in highly modulated turbulence dynamics in the BBL with strong implications for diapycnal mixing (Lorke et al. 2008; Becherer and Umlauf 2011).

As in earlier studies (Bogucki et al. 1997; Klymak and Moum 2003; Scotti and Pineda 2004), we find high acoustic backscatter intensities associated with nearbottom onshore pulses. Since there is no apparent elevation in acoustic backscatter intensity associated with the offshore pulses (Fig. 11), this suggests a net onshore transport of bottom sediments by the action of velocity pulses induced by NLIWs (Bogucki and Redekopp 1999) and has potentially large implications for sediment transport over the inner shelf (e.g., Pomar et al. 2012).

If we apply our results to solitary waves, one implication is that solitary waves of depression interact less strongly with the bottom than solitary waves of elevation. Since depression waves dissipate their energy more slowly, they can transport energy and mass over longer distances than elevation waves.

In this context it is important to note that, for the most part, the NLIWs we have observed over the inner shelf do not typically occur as well-defined solitary waves, but rather as extended wave trains often containing both phases of elevation and depression. What the phase asymmetry in terms of energy dissipation means for the evolution of the entire wave train is not obvious and would provide an interesting subject for further investigations. Events like 28 in Fig. 4f are closest to idealized solitary waves. However, even in this example there is a smaller trailing isopycnal elevation pulse following the initial apparently prototypical solitary wave of depression. In our data from the inner shelf, where the bottom is close to the pycnocline, all waves must interact with the bottom at some level and the nature of the wave behavior includes the process of polarity reversal.

A full comprehension of the asymmetric interaction of NLIWs with the bottom is necessary in order to understand the energy pathways from large-scale internal tides to small-scale dissipation and mixing on the inner shelf. The internal tide generated farther offshore carries significant energy (Colosi et al. 2018). As it propagates onto the inner shelf it breaks up into NLIWs. These NLIWs interact with the bottom and the background stratification, which is in turn modulated by the internal tide in very complicated ways. Our dataset reveals that one of these complications is a systematic asymmetry in the way by which the elevation and depression phases of NLIWs interact with the bottom. This has potentially large implications for sediment and energy transport as well as diapycnal mixing over the inner shelf.

Acknowledgments. The work described here was fully funded by the Office of Naval Research through the Inner Shelf DRI. We acknowledge the efforts of Craig Van Appledorn, Pavan Vutukur and Kerry Latham in building, testing, calibrating, and deploying GusTs. We thank the full host of participants for helping with deployments and for attempting to incorporate GusTs on their platforms, some of which were not well suited for such a device. Sally Warner and Deepak Cherian contributed helpful conversations. We are grateful to reviewers Marek Stastna and Andrew Lucas as well as editor Nicole Jones for their valuable comments that helped to substantially improve the manuscript. We are grateful to Pedro Lomónaco and the team at the Oregon State Hinsdale Wave Research Laboratory for actively supporting the development and testing of the GusT instrument. All data from the entire project are being archived at UC San Diego Library Digital Collections. Immediate access to the data discussed in this manuscript can be requested by email to johannes.becherer@ hzg.de.

\section{APPENDIX}

\section{Computation of $\varepsilon_{p}$}

The use of a pitot-static tube to measure the spectrum of velocity fluctuations due to turbulence, 
from which $\varepsilon_{p}$ can be quantified by scaling, was shown by Moum (2015). Moum (2015) was able to fit the measured velocity spectra against the inertial subrange of the Kolmogorov spectrum (Kolmogorov 1941) at relatively low wavenumbers. This was possible because the data came from a deep bottom lander in a steady mean current without surface wave contamination.

Here we are forced to use a different approach because of strong surface wave orbital velocities at 50-m depth. The orbital velocities were often larger than the mean current. As a consequence, the GusT changes direction on periods corresponding to the low-frequency surface gravity waves (10-20s). Because of this, fitting longer spectra (couple of minutes) as in Moum (2015) is not feasible. Instead, we calculate spectra on 2-s segments and fit these in the dissipative subrange against an empirical spectrum for the longitudinal velocity fluctuations measured by Nasymth (Nasmyth 1970; Oakey 1982),

$$
D_{11}^{\text {nas }}(k)=15 \nu k_{1}^{2} \Phi_{11}(k)=15 \nu L_{k}^{-2}\left(\varepsilon \nu^{5}\right)^{1 / 4} G_{1}\left(k L_{k}\right),
$$

where $D_{11}(k)$ is the dissipation spectrum, $\Phi_{11}(k)$ is the energy spectrum of the longitudinal velocity component, $k$ is the radian wavenumber in sensor direction, $L_{k}=\nu^{3 / 4} \varepsilon^{-(1 / 4)}$ is the Kolmogorov scale, and $\nu$ is the molecular viscosity. ${ }^{\mathrm{A} 1}$ The universal velocity gradient spectrum $G_{1}$, empirically measured by Nasmyth (1970), can be approximated with a functional relation

$$
G_{1}\left(k L_{k}\right)=\frac{6.02\left[k L_{k} /(2 \pi)\right]^{1 / 3}}{2 \pi\left\{1+\left[27.5 k L_{k} /(2 \pi)\right]^{3.7}\right\}}
$$

that is based on a similar expression for the transverse component $G_{2}$ [cf. Eq. (A1) in Wolk et al. 2002].

From pitot tube time series, we calculate 2-s-long energy spectra in frequency space, $\Phi_{11}(f)$, which are converted into dissipation spectra in wavenumber space by making use of Taylor's frozen flow hypnosis (Taylor 1935),

$$
D_{11}^{m}(k)=15 \nu\left(\frac{2 \pi}{\left\langle u_{p}\right\rangle_{2 \mathrm{~s}}} f\right)^{2} \Phi_{11}(f) \frac{d f}{d k}=\frac{30 \pi \nu}{\left\langle u_{p}\right\rangle_{2 \mathrm{~s}}} f^{2} \Phi_{11}(f),
$$

\footnotetext{
${ }^{\mathrm{A} 1}$ Note that the transverse component of the velocity spectrum $\Phi_{22}(k)$ is relevant for shear probe measurements of cross-axis velocity shear (Oakey 1982; Wolk et al. 2002), which yields a prefactor of $15 / 2 \nu$ instead of $15 \nu$ (Pope 2000, p. 132).
}

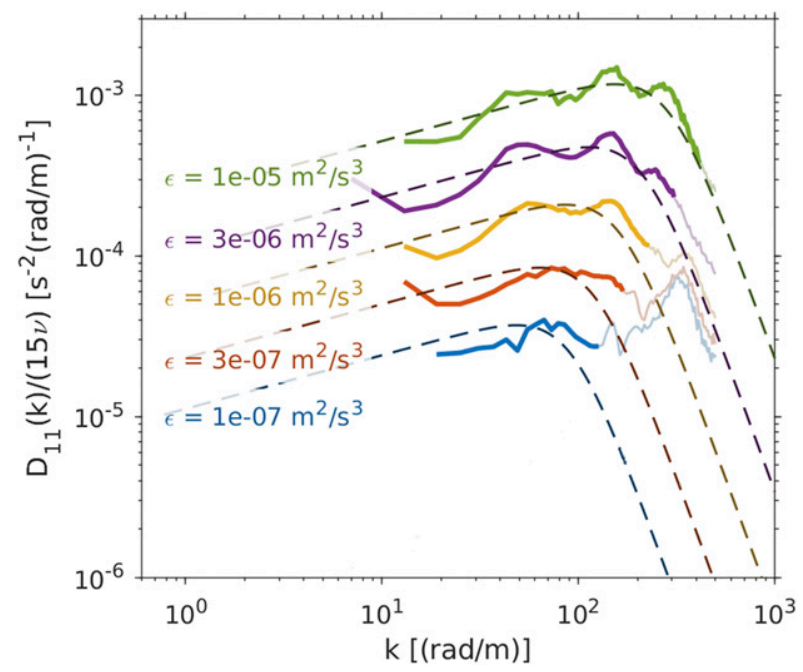

FIG. A1. Thick lines show dissipation spectra based on pitot data. The different colors represent different levels of $\varepsilon_{p}$, where each line corresponds to a spectral average over several 100 individual spectra measured over a period of 3 days. The corresponding thin light shaded lines show parts of the spectrum that were excluded from the fit, based on a cutoff for $k>k_{\text {max }}$. Black dashed lines show the equivalent Nasmyth spectra based on (A1).

where $\left\langle u_{p}\right\rangle_{2 \mathrm{~s}}$ is the 2-s average speed measured by the pitot tube and $f=\left\langle u_{p}\right\rangle_{2 s} k /(2 \pi)$ the frequency. The measured spectrum $D_{11}^{m}(k)$ is integrated over a limited wavenumber band $\left(k_{\min }-k_{\max }\right)$ to get a first estimate of the dissipation rate

$$
\varepsilon^{m}=\int_{k_{\min }}^{k_{\max }} D^{m}(k) d k
$$

This initial value is than used in an iterative procedure to calculate a correction factor based on the Nasmyth spectrum $D_{11}^{\text {nas }}(k)$ from (A1):

$$
\varepsilon_{i+1}=\frac{\int_{0}^{\infty} D^{\mathrm{nas}}\left(k, \varepsilon_{i}\right) d k}{\int_{k_{\min }}^{k_{\max }} D^{\mathrm{nas}}\left(k, \varepsilon_{i}\right) d k} \varepsilon^{m} .
$$

This correction factor usually converges within in couple of iterations. The wavenumber band is set in the low end $k_{\text {min }}$ by the length of the spectrum (2s) and at the high end by $k_{\max }=3 / L_{k}$, which iteratively changes with $\varepsilon_{i+1}$. Examples for averaged spectra for different levels of $\varepsilon$ are illustrated in Fig. A1.

Using this procedure, a single value for $\varepsilon$ is obtained every $2 \mathrm{~s}$. In the case of the deployments discussed in this paper, most of these 2-s values do not provide reliable estimates of $\varepsilon$. The major complication lies in the fact that the wave orbital velocities are often larger than the 
mean currents. As a consequence, the swiveling pitot tube does not always point directly into the flow or measures fluid disturbed by the lander or the GusT itself. Therefore, it is crucial to use a data flagging scheme that avoids contaminated data. Here we use a three-step flagging scheme: 1) We only consider data at the velocity peak of each surface wave cycle which ensures proper alignment of the GusT with the flow as well as undisturbed fluid, 2) the mean current (1 min moving averages) must be above a threshold $\left(0.1 \mathrm{~m} \mathrm{~s}^{-1}\right)$, and 3$)$ the surface wave velocity amplitude must be smaller than the mean current. Steps 2 and 3 ensure that the measured fluid is not already stirred by the lander. The first step rejects about $80 \%-90 \%$ of all 2 -s estimates of $\varepsilon$, and the remaining two steps remove on a 1-min time scale all situations with a very small mean current or too-strong surface waves. This flagging scheme typically removes about $90 \%-95 \%$ of all 2 -s estimates. The remaining $5 \%-10 \%$ are averaged to obtain a continuous time series of turbulence for all situations associated with a sufficient mean current such that the coverage on a 1-min time scale is typically between $30 \%$ and $60 \%$ in the dataset presented here (see Fig. 6d).

\section{REFERENCES}

Aghsaee, P., L. Boegman, and K. G. Lamb, 2010: Breaking of shoaling internal solitary waves. J. Fluid Mech., 659, 289-317, https://doi.org/10.1017/S002211201000248X.

$\longrightarrow$, - P. J. Diamessis, and K. G. Lamb, 2012: Boundary-layerseparation-driven vortex shedding beneath internal solitary waves of depression. J. Fluid Mech., 690, 321-344, https:// doi.org/10.1017/jfm.2011.432.

Allen, R. M., J. A. Simeonov, J. Calantoni, M. T. Stacey, and E. A. Variano, 2018: Turbulence in the presence of internal waves in the bottom boundary layer of the California inner shelf. Ocean Dyn., 68, 627-644, https://doi.org/10.1007/s10236-018-1147-7.

Apel, J. R., 2003: A new analytical model for internal solitons in the ocean. J. Phys. Oceanogr., 33, 2247-2269, https://doi.org/ 10.1175/1520-0485(2003)033<2247:ANAMFI >2.0.CO;2.

Arthur, R. S., and O. B. Fringer, 2014: The dynamics of breaking internal solitary waves on slopes. J. Fluid Mech., 761, 360-398, https://doi.org/10.1017/jfm.2014.641.

Barad, M. F., and O. B. Fringer, 2010: Simulations of shear instabilities in interfacial gravity waves. J. Fluid Mech., 644, 61-95, https://doi.org/10.1017/S0022112009992035.

Becherer, J., and L. Umlauf, 2011: Boundary mixing in lakes: 1. Modeling the effect of shear-induced convection. J. Geophys. Res., 116, C10017, https://doi.org/10.1029/2011JC007119.

__ and J. N. Moum, 2017: An efficient scheme for onboard reduction of moored $\chi$ pod data. J. Atmos. Oceanic Technol., 34, 2533-2546, https://doi.org/10.1175/JTECH-D-17-0118.1.

Boegman, L., and M. Stastna, 2019: Sediment resuspension and transport by internal solitary waves. Annu. Rev. Fluid Mech., 51, 129-154, https://doi.org/10.1146/annurev-fluid-122316-045049.

Bogucki, D., and C. Garrett, 1993: A simple model for the shear-induced decay of an internal solitary wave. J. Phys. Oceanogr., 23, 1767-1776, https://doi.org/10.1175/1520-0485(1993) $023<1767$ :ASMFTS $>2.0$.CO; 2 .
—_, and L. G. Redekopp, 1999: A mechanism for sediment resuspension by internal solitary waves. Geophys. Res. Lett., 26, 1317-1320, https://doi.org/10.1029/1999GL900234.

_ - T. Dickey, and L. G. Redekopp, 1997: Sediment resuspension and mixing by resonantly generated internal solitary waves. J. Phys. Oceanogr., 27, 1181-1196, https://doi.org/10.1175/ 1520-0485(1997)027<1181:SRAMBR >2.0.CO;2.

Bourgault, D., D. E. Kelley, and P. S. Galbraith, 2008: Turbulence and boluses on an internal beach. J. Mar. Res., 66, 563-588, https://doi.org/10.1357/002224008787536835.

Colosi, J. A., N. Kumar, S. H. Suanda, T. M. Freismuth, and J. H. MacMahan, 2018: Statistics of internal tide bores and internal solitary waves observed on the inner continental shelf off Point Sal, California. J. Phys. Oceanogr., 48, 123-143, https:// doi.org/10.1175/JPO-D-17-0045.1.

Diamessis, P. J., and L. G. Redekopp, 2006: Numerical investigation of solitary internal wave-induced global instability in shallow water benthic boundary layers. J. Phys. Oceanogr., 36, 784-812, https://doi.org/10.1175/JPO2900.1.

Gargett, A. E., T. R. Osborn, and P. W. Nasmyth, 1984: Local isotropy and the decay of turbulence in a stratified fluid. J. Fluid Mech., 144, 231-280, https://doi.org/10.1017/S0022112084001592.

Gill, A. E., 2016: Atmosphere-Ocean Dynamics. Elsevier, 662 pp.

Helfrich, K. R., W. K. Melville, and J. W. Miles, 1984: On interfacial solitary waves over slowly varying topography. J. Fluid Mech., 149, 305-317, https://doi.org/10.1017/S0022112084002664.

Henyey, F. S., and A. Hoering, 1997: Energetics of borelike internal waves. J. Geophys. Res., 102, 3323-3330, https://doi.org/ 10.1029/96JC03558.

Holdaway, G. P., P. D. Thorne, D. Flatt, S. E. Jones, and D. Prandle, 1999: Comparison between ADCP and transmissometer measurements of suspended sediment concentration. Cont. Shelf Res., 19, 421-441, https://doi.org/10.1016/S02784343(98)00097-1.

Klymak, J. M., and J. N. Moum, 2003: Internal solitary waves of elevation advancing on a shoaling shelf. Geophys. Res. Lett., 30, 2045, https://doi.org/10.1029/2003GL017706.

- M. H. Alford, R. Pinkel, R.-C. Lien, Y. J. Yang, and T.-Y. Tang, 2011: The breaking and scattering of the internal tide on a continental slope. J. Phys. Oceanogr., 41, 926-945, https:// doi.org/10.1175/2010JPO4500.1.

Kolmogorov, A. N., 1941: The local structure of turbulence in incompressible viscous fluid for very large Reynolds numbers. Dokl. Akad. Nauk SSSR, 30, 299-303.

Kumar, N., S. Suanda, J. Colosi, K. Haas, E. DiLorenzo, A. Miller, and C. Edwards, 2019: Coastal semidiurnal internal tidal incoherence in the Santa Maria Basin, California: Observations and model simulations. J. Geophys. Res. Oceans, 124, 51585179, https://doi.org/10.1029/2018JC014891.

Lamb, K. G., 2014: Internal wave breaking and dissipation mechanisms on the continental slope/shelf. Annu. Rev. Fluid Mech., 46, 231-254, https://doi.org/10.1146/annurev-fluid-011212-140701.

— , and D. Farmer, 2011: Instabilities in an internal solitary-like wave on the Oregon shelf. J. Phys. Oceanogr., 41, 67-87, https://doi.org/10.1175/2010JPO4308.1.

Lerczak, J., and Coauthors, 2019: Untangling the interconnected dynamics of the ocean's inner continental shelf. Eos, Trans. Amer. Geophys. Union, 100, https://doi.org/10.1029/2019EO122141.

Lorke, A., L. Umlauf, and V. Mohrholz, 2008: Stratification and mixing on sloping boundaries. Geophys. Res. Lett., 35, L14610, https://doi.org/10.1029/2008GL034607.

McSweeney, J. M., and Coauthors, 2020: Observations of shoaling nonlinear internal bores across the central California inner 
shelf. J. Phys. Oceanogr., 50, 111-132, https://doi.org/10.1175/ JPO-D-19-0125.1.

Moum, J. N., 2015: Ocean speed and turbulence measurements using pitot-static tubes on moorings. J. Atmos. Oceanic Technol., 32 1400-1413, https://doi.org/10.1175/JTECH-D-14-00158.1.

—, and W. Smyth, 2006: The pressure disturbance of a nonlinear internal wave train. J. Fluid Mech., 558, 153-177, https:// doi.org/10.1017/S0022112006000036.

—_, and J. Nash, 2008: Seafloor pressure measurements of nonlinear internal waves. J. Phys. Oceanogr., 38, 481-491, https:// doi.org/10.1175/2007JPO3736.1.

__ and _ 2009: Mixing measurements on an equatorial ocean mooring. J. Atmos. Oceanic Technol., 26, 317-336, https:// doi.org/10.1175/2008JTECHO617.1.

_ D. Farmer, W. Smyth, L. Armi, and S. Vagle, 2003: Structure and generation of turbulence at interfaces strained by internal solitary waves propagating shoreward over the continental shelf. J. Phys. Oceanogr., 33, 2093-2112, https://doi.org/10.1175/ 1520-0485(2003)033<2093:SAGOTA > 2.0.CO;2.

_ J. Klymak, J. Nash, A. Perlin, and W. Smyth, 2007: Energy transport by nonlinear internal waves. J. Phys. Oceanogr., 37, 1968-1988, https://doi.org/10.1175/JPO3094.1.

Narasimha, R., and K. Sreenivasan, 1973: Relaminarization in highly accelerated turbulent boundary layers. J. Fluid Mech., 61, 417-447, https://doi.org/10.1017/S0022112073000790.

Nash, J. D., and J. N. Moum, 2005: River plumes as a source of large-amplitude internal waves in the coastal ocean. Nature, 437, 400-403, https://doi.org/10.1038/nature03936.

— S. M. Kelly, E. L. Shroyer, J. N. Moum, and T. F. Duda, 2012: The unpredictable nature of internal tides on continental shelves. J. Phys. Oceanogr., 42, 1981-2000, https://doi.org/ 10.1175/JPO-D-12-028.1.

Nasmyth, P. W., 1970: Oceanic turbulence. Ph.D. thesis, University of British Columbia, 69 pp.

Oakey, N., 1982: Determination of the rate of dissipation of turbulent energy from simultaneous temperature and velocity shear microstructure measurements. J. Phys. Oceanogr., 12, 256-271, https://doi.org/10.1175/1520-0485(1982)012<0256: DOTROD $>2.0 . \mathrm{CO} ; 2$

Perlin, A., and J. N. Moum, 2012: Comparison of thermal variance dissipation rates from moored and profiling instruments at the equator. J. Atmos. Oceanic Technol., 29, 1347-1362, https:// doi.org/10.1175/JTECH-D-12-00019.1.

- _ - J. Klymak, M. D. Levine, T. Boyd, and P. M. Kosro, 2005: A modified law-of-the-wall applied to oceanic bottom boundary layers. J. Geophys. Res., 110, C10S10, https:// doi.org/10.1029/2004JC002310.

Pomar, L., M. Morsilli, P. Hallock, and B. Bádenas, 2012: Internal waves, an under-explored source of turbulence events in the sedimentary record. Earth-Sci. Rev., 111, 56-81, https://doi.org/ 10.1016/j.earscirev.2011.12.005.

Pope, S. B., 2000: Turbulent Flows. Cambridge University Press, $771 \mathrm{pp}$.

Pujiana, K., J. Moum, and W. Smyth, 2018: The role of turbulence in redistributing upper ocean heat, freshwater, and momentum in response to the MJO in the equatorial Indian Ocean. J. Phys. Oceanogr., 48, 197-220, https://doi.org/10.1175/JPO-D-17-0146.1.

Sandstrom, H., and J. Elliott, 1984: Internal tide and solitons on the Scotian Shelf: A nutrient pump at work. J. Geophys. Res., 89, 6415-6426, https://doi.org/10.1029/JC089iC04p06415.

_ waves. J. Phys. Oceanogr., 25, 604-614, https://doi.org/10.1175/ 1520-0485(1995)025<0604:DIITAS >2.0.CO;2.
Schlichting, H., and K. Gersten, 2016: Boundary-Layer Theory. Springer, $805 \mathrm{pp}$.

Scotti, A., and J. Pineda, 2004: Observation of very large and steep internal waves of elevation near the Massachusetts coast. Geophys. Res. Lett., 31, L22307, https://doi.org/10.1029/2004GL021052.

Shroyer, E. L., J. Moum, and J. Nash, 2009: Observations of polarity reversal in shoaling nonlinear internal waves. J. Phys. Oceanogr., 39, 691-701, https://doi.org/10.1175/2008JPO3953.1.

- J. N. Moum, and J. D. Nash, 2010: Vertical heat flux and lateral mass transport in nonlinear internal waves. Geophys. Res. Lett., 37, L08601, https://doi.org/10.1029/2010GL042715.

Smyth, W. D., and J. R. Carpenter, 2019: Instability in Geophysical Flows. Cambridge University Press, 328 pp.

Stastna, M., and K. G. Lamb, 2002: Vortex shedding and sediment resuspension associated with the interaction of an internal solitary wave and the bottom boundary layer. Geophys. Res. Lett., 29, 1512, https://doi.org/10.1029/2001GL014070.

$\longrightarrow$, and — 2008: Sediment resuspension mechanisms associated with internal waves in coastal waters. J. Geophys. Res., 113, C10016, https://doi.org/10.1029/2007JC004711.

Stöeber, U., and J. N. Moum, 2011: On the potential for automated realtime detection of nonlinear internal waves from seafloor pressure measurements. Appl. Ocean Res., 33, 275-285, https:// doi.org/10.1016/j.apor.2011.07.007.

Taylor, G. I., 1935: Statistical theory of turbulence. Proc. Roy. Soc. London, A151, 421-444, https://doi.org/10.1098/RSPA.1935.0158.

Tennekes, H., and J. L. Lumley, 1972: A First Course in Turbulence. MIT Press, 300 pp.

Venayagamoorthy, S. K., and O. B. Fringer, 2007: On the formation and propagation of nonlinear internal boluses across a shelf break. J. Fluid Mech., 577, 137-159, https://doi.org/ 10.1017/S0022112007004624.

Vlasenko, V., and K. Hutter, 2002: Numerical experiments on the breaking of solitary internal waves over a slope-shelf topography. J. Phys. Oceanogr., 32, 1779-1793, https://doi.org/ 10.1175/1520-0485(2002)032<1779:NEOTBO > 2.0.CO;2.

Walter, R. K., C. B. Woodson, R. S. Arthur, O. B. Fringer, and S. G. Monismith, 2012: Nearshore internal bores and turbulent mixing in southern Monterey Bay. J. Geophys. Res., 117, C07017, https://doi.org/10.1029/2012JC008115.

, M. E. Squibb, C. B. Woodson, J. R. Koseff, and S. G. Monismith, 2014: Stratified turbulence in the nearshore coastal ocean: Dynamics and evolution in the presence of internal bores. J. Geophys. Res. Oceans, 119, 8709-8730, https://doi.org/ 10.1002/2014JC010396.

Warner, S. J., P. MacCready, J. N. Moum, and J. D. Nash, 2013: Measurement of tidal form drag using seafloor pressure sensors. J. Phys. Oceanogr., 43, 1150-1172, https://doi.org/10.1175/JPOD-12-0163.1.

Wolk, F., H. Yamazaki, L. Seuront, and R. G. Lueck, 2002: A new free-fall profiler for measuring biophysical microstructure. J. Atmos. Oceanic Technol., 19, 780-793, https://doi.org/ 10.1175/1520-0426(2002)019<0780:ANFFPF>2.0.CO;2.

Zhang, Y., and J. N. Moum, 2010: Inertial-convective subrange estimates of thermal variance dissipation rate from moored temperature measurements. J. Atmos. Oceanic Technol., 27, 1950-1959, https://doi.org/10.1175/2010JTECHO746.1.

Zulberti, A., G. Ivey, and N. Jones, 2018: Observations of nearbed stress beneath nonlinear internal wave trains in the ocean. 21st Australasian Fluid Mechanics Conf., Adelaide, SA, Australia, Australasian Fluid Mechanics Society, 652, https://people.eng.unimelb.edu.au/imarusic/proceedings/21/ Contribution_652_final.pdf. 